\title{
Neural Mechanisms of Motor Program Switching in Aplysia
}

\author{
Jian Jing and Klaudiusz R. Weiss \\ Department of Physiology and Biophysics, Mount Sinai School of Medicine, New York, New York 10029-6574
}

The Aplysia multifunctional feeding central pattern generator (CPG) produces at least two types of motor programs, ingestion and egestion, that involve two sets of radula movements, protraction-retraction and opening-closing movements. In ingestion, the radula closes during retraction to pull food in, whereas in egestion, the radula closes during protraction to push inedible objects out. Thus, radula closure shifts the phase in which it occurs with respect to protraction-retraction in the two programs. To identify the central switching mechanisms, we compared activity of CPG neurons during the two types of motor programs elicited by a higher-order interneuron, cerebral-buccal interneuron-2 (CBI-2). Although CPG elements (B63, B34, and B64) that mediate the protraction-retraction sequence are active in both programs, two other CPG elements, B20 and B4/5, are preferentially active in egestive programs and play a major role in mediating CBI-2-elicited egestive programs. Both $\mathrm{B} 20$ and $\mathrm{B} 4 / 5$ control the phasing of radula closure motoneurons (B8 and B16) to ensure that, in egestive programs, these motoneurons fire and produce radula-closing movements only during protraction. Elsewhere, another higherorder interneuron, $\mathrm{CBI}-3$, was shown to convert $\mathrm{CBI}-2$-elicited egestion to ingestion. We show that $\mathrm{CBI}-3$ switches the programs by suppressing the activity of $\mathrm{B} 20$ and $\mathrm{B} 4 / 5$. CBI-3, active only during protraction, accomplishes this through fast inhibition of B20 during protraction and slow inhibition of B4/5 during retraction. The slow inhibition is mimicked and occluded by APGWamide, a neuropeptide contained in CBI-3. Thus, fast conventional and slow peptidergic transmissions originating from the same interneuron act in concert to meet specific temporal requirements in pattern switching.

Key words: Aplysia; feeding; ingestion; egestion; central pattern generator; mollusk; motor program switching; motor pattern selection; APGWamide; neuropeptide; dopaminergic neurons
The ability to select an appropriate behavior enhances an organism's chances of successful adaptation. One type of behavioral selection involves selection of a specific motor pattern from a set of rhythmic patterns produced by partially overlapping populations of motoneurons and muscles. Because such sets of related rhythmic behaviors are generated by multifunctional central pattern generators (CPGs; Delcomyn, 1980; Marder and Calabrese, 1996), it is of great interest to determine how such networks are functionally reorganized to produce different motor patterns. In a number of systems, reconfiguration of CPGs is found to be mediated by higher-order neurons (projection neurons) that act on the CPG (Croll et al., 1985; Rosen et al., 1991; Dickinson and Moulins, 1992; Meyrand et al., 1994; Blitz and Nusbaum, 1997; Combes et al., 1999a; Jing and Weiss, 2000). Additionally, modulatory transmitters, some of which are present in projection neurons, can reconfigure CPGs (Harris-Warrick and Marder, 1991; Stein et al., 1997). Thus, longer-lasting modulation, in some cases together with phasic synaptic activity (Blitz and Nusbaum, 1999), may contribute to motor pattern switching that is mediated by projection neurons.

In response to various sensory stimuli, Aplysia can rapidly switch among multiple forms of feeding-related behaviors (Kup-

Received May 22, 2001; revised July 3, 2001; accepted July 3, 2001.

This research was supported by National Institutes of Health Grants RO1 MH50235, KO5 MH 01427, T32 DA07135, and F32 MH12890. The National Resource for Aplysia of the University of Miami provided some of the animals used in this study under Grant RR-10294 from the National Center for Research Resources, National Institutes of Health. We thank Dr. E. C. Cropper for useful comments on this manuscript.

Correspondence should be addressed to Jian Jing, Department of Physiology and Biophysics, Box 1218, Mount Sinai School of Medicine, 1 Gustave Levy Place, New York, NY 10029-6574. E-mail: jjing@inka.mssm.edu.

Copyright (C) 2001 Society for Neuroscience $\quad 0270-6474 / 01 / 217349-14 \$ 15.00 / 0$ fermann, 1974). The expression of a specific feeding behavior is also regulated by an animal's motivational state and learning (Kupfermann, 1974; Weiss et al., 1982; Susswein et al., 1986; Nargeot et al., 1997; Lechner et al., 2000). The switch between ingestive and egestive behaviors is characterized by a phase shift of radula closure with respect to protraction-retraction (Morton and Chiel, 1993a,b). Recent work (Morgan et al., 2001) demonstrated that stimulation of the command-like neuron, cerebralbuccal interneuron-2 (CBI-2), can elicit both ingestive and egestive motor programs. In addition, costimulation of CBI-3 with CBI-2 causes egestive programs to become ingestive. The neuropeptide APGWamide, which is contained in CBI-3, mimics the program switching actions of CBI-3. Because differing stimuli can activate CBI-2 alone or CBI-2 together with CBI-3, the two motor programs elicited by different combinations of CBIs are probably behaviorally relevant.

We undertook this study to elucidate the mechanisms that permit CBI-2 stimulation to produce both ingestive and egestive motor programs and to identify the mechanisms through which CBI-3 and APGWamide convert CBI-2-elicited egestive programs to ingestive ones. Specifically, we sought to determine whether CBI-3 acts directly on motoneurons or via interneurons to produce the switch. We found that CBI-3 switches motor programs by inhibiting two CPG elements that determine the phasing of radula closure motoneurons during egestion. Moreover, APGWamide may mediate the slow inhibition that CBI-3 exerts on one of its targets. Interestingly, although switching in the crustacean gastric mill (Combes et al., 1999a) is similar to that of Aplysia at the level of motoneurons, the gastric mill switch does not require modulation and is implemented by direct phasic inhibition of motoneurons by a projection neuron. Comparison of 
the two circuits provides insights into how differences in the organization of the crustacean and Aplysia CPGs may necessitate the use of modulation for program switching in one circuit but not the other.

Parts of this paper have been published previously in abstract form (Jing et al., 1999; Jing and Weiss, 2000).

\section{MATERIALS AND METHODS}

Specimens of Aplysia californica were obtained from Marinus (Long Beach, CA) and from the National Resource for Aplysia (University of Miami, Miami, FL). They were maintained in circulating artificial seawater (ASW) made from Instant Ocean (Aquarium Systems, Mentor, $\mathrm{OH})$ at $14-15^{\circ} \mathrm{C}$. Animals weighing $30-300 \mathrm{gm}$ were anesthetized by injection ( $50 \%$ of the body weight) of isotonic $\mathrm{MgCl}_{2}(337 \mathrm{~mm})$. Cerebral ganglia together with buccal ganglia were dissected out. Connective tissue surrounding ganglia was removed, whereas ganglia were bathed in a solution containing half ASW (in mM: $460 \mathrm{NaCl}, 10 \mathrm{KCl}, 55 \mathrm{MgCl}_{2}, 11$ $\mathrm{CaCl}_{2}$, and $10 \mathrm{HEPES}$ buffer, $\mathrm{pH}$ 7.6) and half isotonic $\mathrm{MgCl}_{2}$. This solution was then replaced with ASW. All chemicals were purchased from Sigma (St. Louis, MO), unless otherwise stated. Experiments were conducted at $15-19^{\circ} \mathrm{C}$.

Conventional intracellular recordings were obtained using glass microelectrodes filled with $2 \mathrm{M}$ postassium acetate and beveled to 6-12 $\mathrm{M} \Omega$. Extracellular recordings were made using suction electrodes that were manufactured from polyethylene tubing. Data were recorded on a chart recorder (MT9500; Astro-Med, West Warwick, RI) and a pulse code modulation recorder (3000A; Vetter, Rebersburg, PA). Data were digitized and analyzed using Axoscope (Axon Instruments, Union City, CA) and plotted using Axum (Mathsoft, Cambridge, MA). Functional synaptic connections were examined in normal saline, and the ability of PSPs to follow one-for-one presynaptic spikes was taken as an indication of probable monosynapticity. Assays of monosynapticity were conducted in high-divalent saline (in mu: $312 \mathrm{NaCl}, 10 \mathrm{KCl}, 132 \mathrm{MgCl}_{2}, 33 \mathrm{CaCl}_{2}$, and 10 HEPES, pH 7.6), a solution that elevates spike thresholds and thus curtails polysynaptic activation. Electrical coupling was assayed by passing hyperpolarizing current into one cell and measuring alterations of steady-state membrane potential in its partner. The steady-state coupling coefficient was taken as the ratio of the postsynaptic to presynaptic voltage change. Immediately before each measurement of the coupling ratio, the bridge was balanced. Because of the large size of $\mathrm{B} 4 / 5$, the excitability of these neurons was tested using two independent electrodes. One electrode was used for current injection, and one was used for recording.

Identification of neurons and synaptic connections. Neurons were identified on the basis of location, size, and electrophysiological and morphological characteristics. Additional criteria were also used to verify the identity of the cells. CBI-2 was distinguished from the adjacent CBI-12 on the basis of the size of CBI-2 and its more lateral location and stronger ability to drive buccal motor programs (Hurwitz et al., 1999). Recently, CBI-2 was shown to be electrically coupled to CBI-3 (Morgan et al., 2001). To determine whether this connection could be used as an additional criterion to distinguish CBI-2 from CBI-12, we identified CBI-2, CBI-12, and CBI-3 in the same preparations and found that CBI-2 but not CBI-12 was electrically coupled to CBI-3. Thus, the electrical coupling of CBI-2 with CBI-3 was routinely used to verify whether the candidate neuron was CBI-2. The identification of the dopaminergic B20 was verified by paraformaldehyde/glutaraldehyde (FaGlu) histochemistry as described previously (Teyke et al., 1993). Specifically, on completion of physiological experiments, the putative B20 was injected with $3 \%$ rhodamine-lissamine by hyperpolarizing current. The buccal ganglion was then fixed with $4 \%$ paraformaldehyde plus $0.5 \%$ glutaraldehyde. This FaGlu fixation procedure causes catecholamine-containing neurons to fluoresce under UV light. The fixative was washed, and the preparations were viewed with a fluorescence microscope with appropriate filter packs.

Because B20 is located on the rostral surface of the buccal ganglion, whereas other protraction phase neurons, B31/32, B34, B63, and B65, are located on the caudal surface, we were able to investigate only the contralateral connections that B20 makes with these other neurons. To obtain recordings of these contralateral neuronal pairs, the two buccal hemiganglia were twisted at the commissure so that the caudal surface of one hemiganglion was facing up and the rostral surface of the contralateral hemiganglion was facing up.

Classification of fictive motor programs. In the present study, the CBI- 2-elicited motor programs were identified as ingestive or egestive on the basis of phase relations of radula closures with respect to protractionretraction sequences (Fig. 1). The protraction phase was monitored by activity of protraction phase motoneurons and interneurons B31/32, B61/62 (Susswein and Byrne, 1988; Hurwitz et al., 1994, 1996), B34, B63 (Hurwitz et al., 1997), and B20 (Teyke et al., 1993) or by activity in the I 2 nerve. The I 2 nerve contains axons of $\mathrm{B} 31 / 32$ and $\mathrm{B} 61 / 62$. The retraction phase was monitored by depolarization or spikes in $\mathrm{B} 4 / 5$ or B64 (Hurwitz and Susswein, 1996), activity in buccal nerve 2, and by periods of hyperpolarization of protraction phase neurons after the protraction phase ended. Radula closure was monitored by activity of B8 or B16 or the activity in the radula nerve (RN; Cropper et al., 1990; Morton and Chiel, 1993a,b; Church and Lloyd, 1994). The RN contains axons of the B8 neurons. Motor programs were classified as ingestive motor programs when $>50 \%$ of the radula closure activity occurred during the retraction phase, and they were classified as egestive motor programs when there was strong firing of radula closure motoneurons during protraction but few spikes during retraction (cf. Nargeot et al., 1997; Morgan et al., 2001). These criteria were developed on the basis of a combination of studies that were performed on intact animals (Cropper et al., 1990; Morton and Chiel, 1993a) and semi-intact preparations (Morton and Chiel, 1993b; Church and Lloyd, 1994). In addition, we used information derived from cluster analysis of different motor patterns (Morgan, 1999; Morgan et al., 2001).

Peptide application. In all peptide application experiments, desheathed ganglia were pinned in a chamber that had a volume of $\sim 1.5 \mathrm{ml}$. The preparation was continuously perfused at a rate of $0.3 \mathrm{ml} / \mathrm{min}$ and maintained at $\sim 15^{\circ} \mathrm{C}$. The peptide was applied by replacing the ASW perfusate with a perfusate consisting of ASW with freshly dissolved peptides. APGWamide was purchased from AnaSpec Inc. (San Jose, CA).

Throughout Results, $n$ refers to the number of preparations.

\section{RESULTS}

\section{Buccal CPG elements B20 and B4/5 mediate egestive- like motor programs induced by $\mathrm{CBI}-2$ stimulation}

CBI-2 is considered a command-like neuron because it is activated by sensory stimuli that are known to evoke feeding-related behaviors and because CBI-2 stimulation evokes feeding-like motor programs (Rosen et al., 1991; Church and Lloyd, 1994; Sanchez and Kirk, 2000; Morgan et al., 2001). In the isolated CNS, CBI-2 stimulation can elicit ingestive motor programs (Church and Lloyd, 1994). In semi-intact preparations, CBI-2 induces behavior that resembles one specific type of ingestion, biting (Rosen et al., 1988, 1997). However, recent work (Morgan et al., 2001) has shown that in addition to ingestive motor programs, CBI-2 stimulation can also drive egestive motor programs. Moreover, when CBI-2 stimulation evokes egestive programs, costimulation of the electrically coupled CBI-3 converts egestive programs into ingestive ones. Importantly, CBI-3 on its own does not drive any motor program. Thus, CBI-3 acts as a switch from egestive to ingestive motor programs.

To study the mechanisms that determine whether buccal ganglia generate ingestive or egestive behaviors, we first sought to identify the buccal CPG neurons that are differentially active in the two types of motor programs. We induced motor programs by stimulating CBI-2 and examined the activity level of buccal CPG elements. Consistent with the other study (Morgan et al., 2001), we found that CBI- 2 could induce either ingestive- or egestivelike motor programs (Fig. 1). Among the buccal neurons that are considered to be elements of the feeding CPG, we found two neurons that are more active in egestive programs than they are in ingestive programs. We classified these two neurons, B20 and $\mathrm{B} 4 / 5$, as candidate neurons that may mediate motor program switching. The first cell is a dopaminergic buccal-cerebral interneuron, B20, that has previously been shown to be active during the protraction phase of CBI-2-evoked motor programs (Teyke et al., 1993). However, Teyke et al. (1993) did not determine whether 


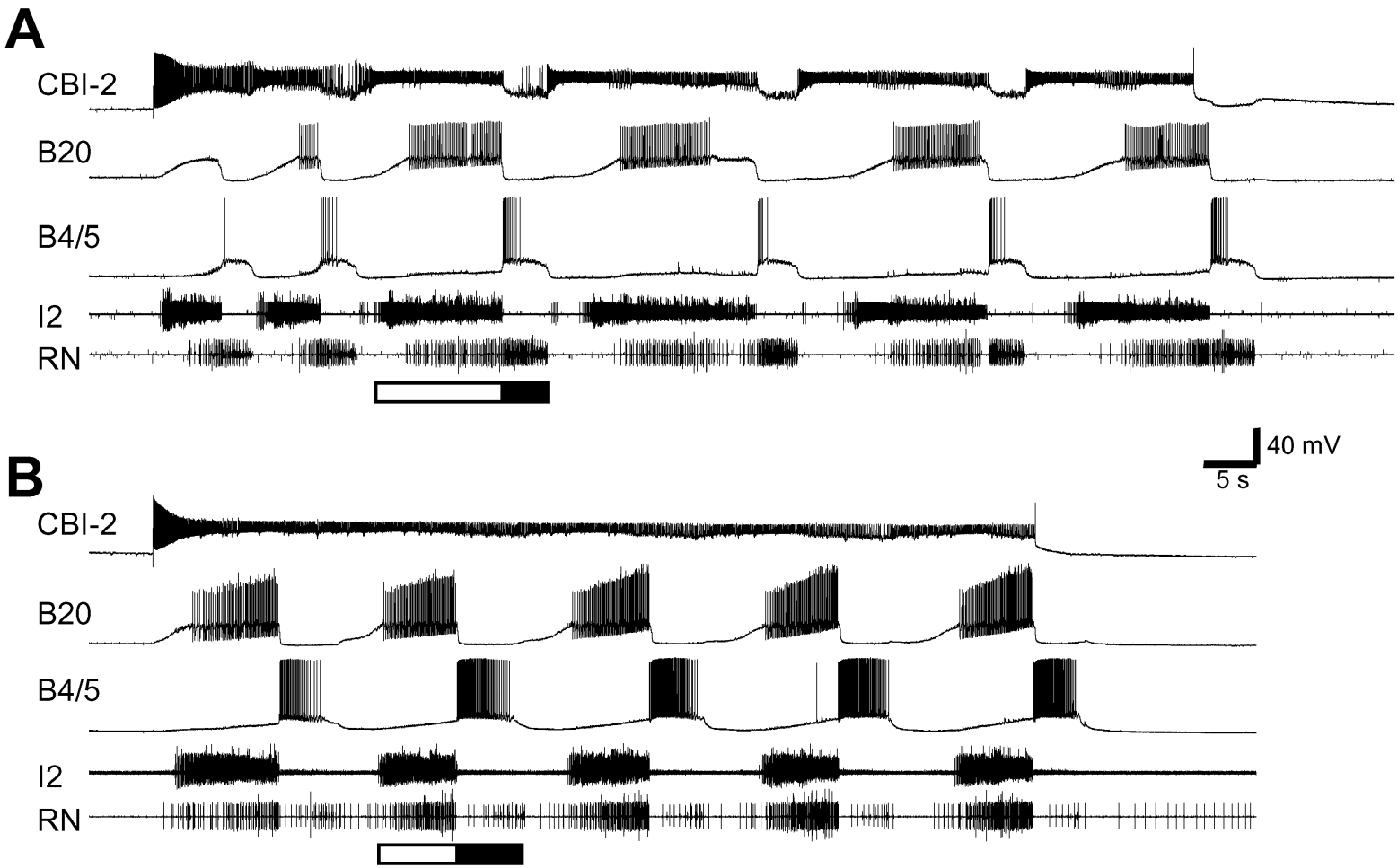

Figure 1. CBI-2 drives both ingestive- and egestive-like motor programs in an isolated CNS. Constant-current injection into CBI-2 induced cyclic activity of the protraction phase interneuron B20 and the retraction phase neuron B4/5. Rhythmic activity was also induced in the I2 and RNs. The protraction phase (open bar) is defined by activity in the I2, which contains axons of the protraction phase motoneurons B31/32 and B61/62. The retraction phase ( filled bar) is defined by sustained depolarization of B4/5 and the hyperpolarization of B20 that follow the protraction phase. Radula closure activity is monitored on the basis of activity in the $\mathrm{RN}$, which contains axons of the radula closure motoneurons $\mathrm{B} 8$. $A, \mathrm{RN}$ activity primarily occurred during the retraction phase; thus the motor program was ingestive. $B, \mathrm{RN}$ activity primarily occurred during the protraction phase; thus the motor program was egestive. Notice that in $B$, neurons B20 and B4/5 displayed higher levels of activity than in $A$.

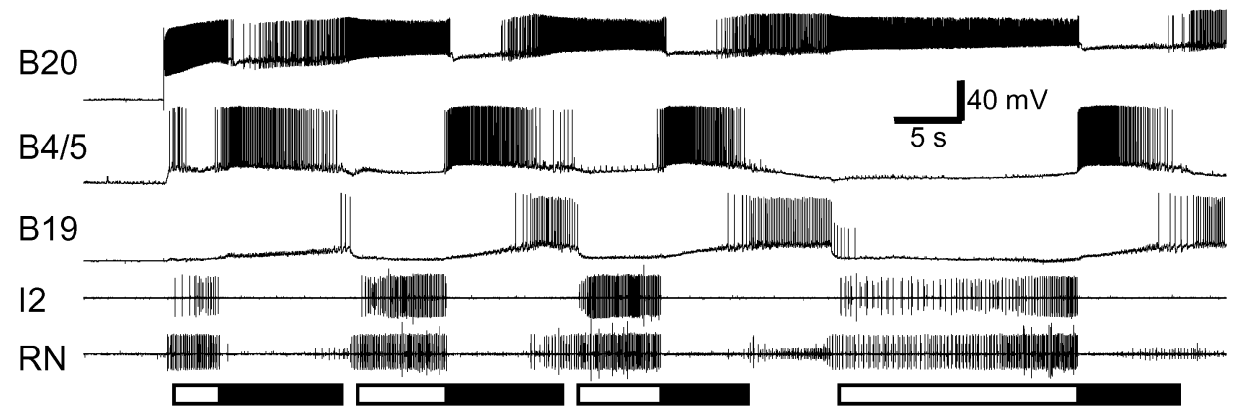

Figure 2. B20 drives egestive motor programs. DC current injection into neuron B20 induced a feeding motor program. Rhythmic activity was recorded in $\mathrm{B} 20, \mathrm{~B} 4 / 5, \mathrm{~B} 19$, the $\mathrm{I} 2$ nerve, and RNs. Radula closure activity $(R N)$ occurred only during protraction (see activity in the I2 nerve; open bar), not during retraction (filled bar), thus indicating that the motor program was egestive. Note that similar to egestive motor programs induced by CBI-2, B4/5 fired strongly in B20-elicited egestive motor programs.

those motor programs evoked by CBI-2 were ingestive or egestive. We found that B20 was strongly activated during CBI-2-elicited egestive motor programs (average firing rate, $>9 \mathrm{~Hz} ; n=11$ ). In contrast, it was only weakly active or did not fire at all during CBI-2-elicited ingestive motor programs (average firing rate, $<7$ $\mathrm{Hz} ; n=19$; Fig. 1; an additional analytical illustration of the role of B20 is shown in Fig. 11).

In addition, Teyke et al. (1993) has shown that B20 can elicit rhythmic buccal motor programs, but they have not determined whether these programs were ingestive or egestive. Consistent with our observation that B20 was more active in CBI-2-elicited egestive programs, we found that motor programs elicited by direct stimulation of B20 were egestive (Fig. 2). Specifically, B20 elicited rhythmic programs that incorporated bursting activity in B20 itself, B4/5, and the buccal-cerebral interneuron B19 (Rosen et al., 2000). These motor programs were classified as egestive because activity in the RN occurred primarily during the protraction phase ( $n=22$; Fig. 2 ).

The above experiments suggest that B20 may be sufficient to mediate CBI-2-elicited egestive motor programs. However, these observations do not preclude the possibility that CBI-2 simultaneously recruits additional, as yet unidentified, buccal neurons to induce egestive motor programs. To investigate this possibility, we hyperpolarized B20 during CBI-2-elicited egestive motor programs ( $n=3$; Fig. 3 ) and showed that additional neurons are unlikely to exist. Bilateral recordings and current injections of both B20s were used, because one B20 may still be active when the other is hyperpolarized. CBI-2 stimulation induced strong firing of both B20s (average firing rate, $\sim 11 \mathrm{~Hz}$ ), and the motor programs were egestive-like (i.e., the radula closure motoneuron B8 fired only during the protraction phase) (Fig. $3 A, C$ ). However, when both $\mathrm{B} 20 \mathrm{~s}$ were hyperpolarized, the motor programs be- 

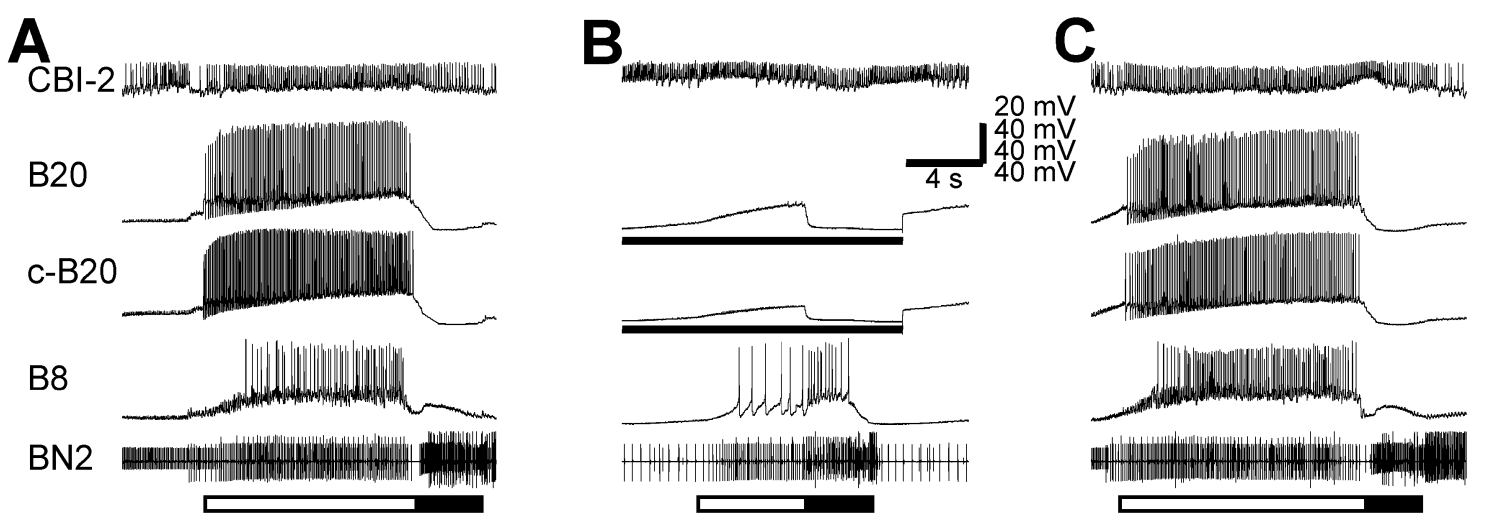

Figure 3. Protraction phase interneuron B20 is necessary for expression of CBI-2-elicited egestive motor programs. $A$, $C$, Stimulation of CBI-2 with DC current injection induced egestive motor programs, because the radula closure motoneuron B8 was active only during protraction (open bar), not during retraction ( filled bar). Note that both the ipsilateral B20 and c-B20 are strongly active. B, When B20 neurons were bilaterally hyperpolarized (bars under $B 20$ recordings), the radula closure motoneuron B8 became predominantly active during the retraction phase, thus indicating an ingestive motor program. BN2, Buccal nerve 2.
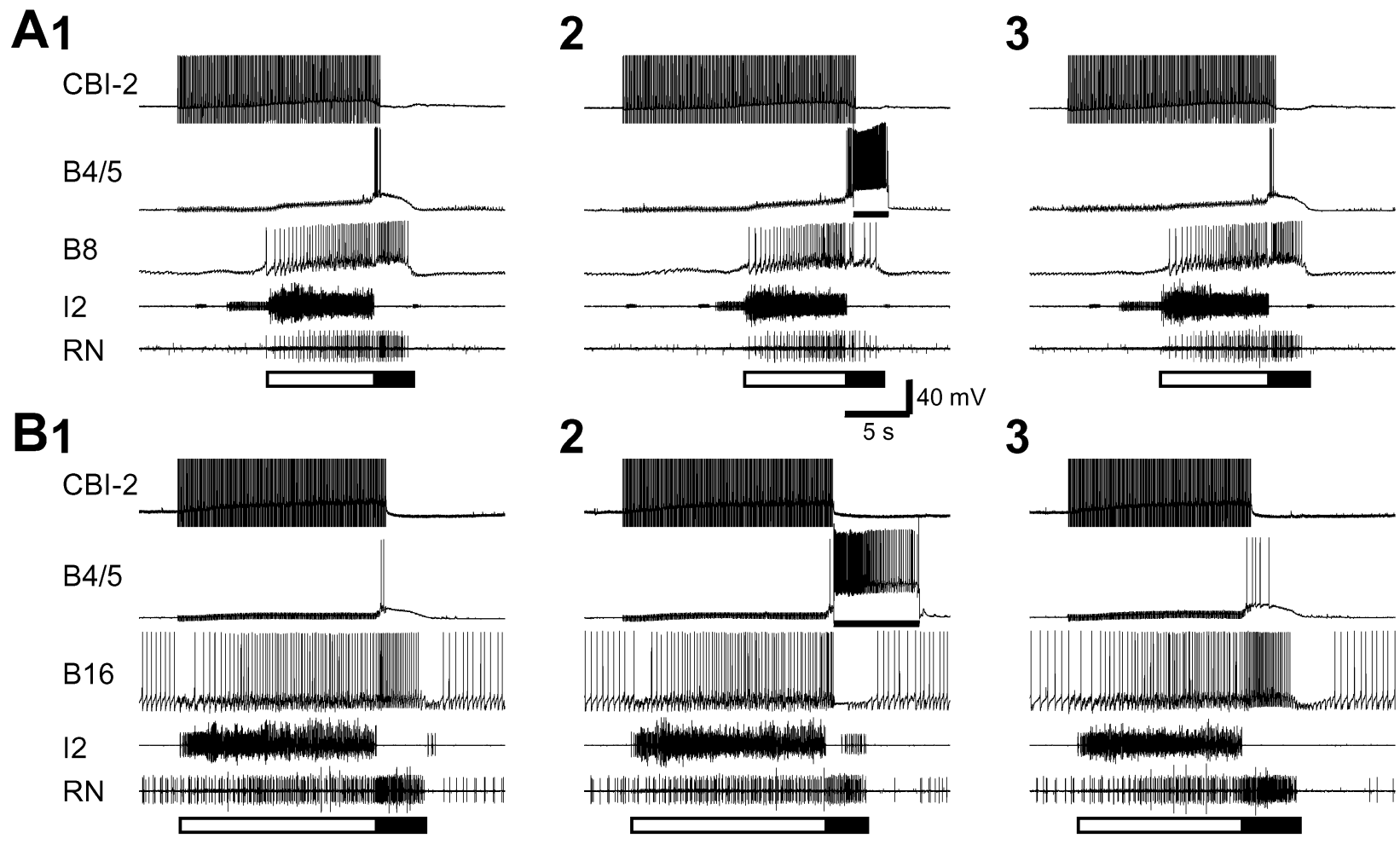

2

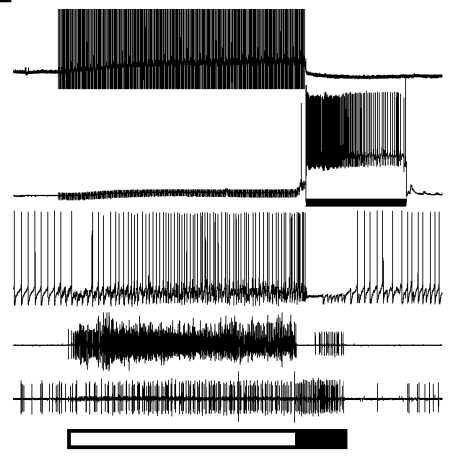

3

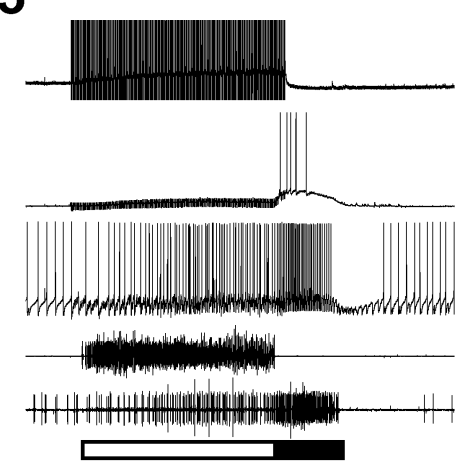

Figure 4. Multiaction retraction phase neuron B4/5 suppresses the activity of the ipsilateral radula closure motoneurons B8 and B16 during the retraction phase of CBI-2-elicited ingestive programs. One cycle of a feeding motor program was elicited by stimulation of CBI-2 with brief current pulses at $12 \mathrm{~Hz}(A)$ or $16 \mathrm{~Hz}(B)$. In the motor programs elicited by CBI-2 $(A, 1,3, B, 1,3)$, the RN activity primarily occurred during the retraction phase (defined as sustained depolarization in B4/5; filled bar) that followed the protraction phase (defined as bursting in the I2 nerve; open bar), thus suggesting that these motor programs were ingestive. Consistently, radula closing motoneurons $\mathrm{B} 8(A, 1,3)$ and $\mathrm{B} 16(B, 1,3)$ fired more spikes (average firing rates: B8, $\sim 8.9 \mathrm{~Hz} ; \mathrm{B} 16, \sim 9.2 \mathrm{~Hz}$ ), and B4/5 fired fewer spikes during the retraction phase. However, when B4/5 was depolarized to fire ( $A$, 2, $B, 2$, bars) during the retraction phase, the activity of the ipsilateral $\mathrm{B} 8(A, 2)$ and $\mathrm{B} 16(B, 2)$ was mostly eliminated. Note that RN contains axons from both ipsilateral and contralateral B8 neurons, and because B4/5 inhibits only ipsilateral B8 neurons, some activity remained in RN during retraction when B4/5 was stimulated.

came ingestive-like, because the most prominent firing of B8 now occurred during the retraction phase (Fig. $3 B$ ). Thus, recruitment of B20 is necessary for the expression of CBI-2-elicited egestive motor programs.

The second potential switch neuron is actually two virtually identical cells, the multiaction neurons B4 and B5 (Gardner, 1971, 1977). B4/5 is normally active during the retraction phase of feeding motor programs. The activity of B4/5 during different types of feeding motor programs has been examined in isolated CNS and semi-intact and intact preparations in several previous studies (Church and Lloyd, 1994; Warman and Chiel, 1995; Morgan et al., 2001). These studies suggest that B4/5 is more active during egestive than ingestive motor programs and behaviors. Our data are consistent with those previous reports. In particular, we verified the differential activity of B4/5 in ingestive and egestive motor programs elicited by CBI-2 (Fig. 1). Typically, 

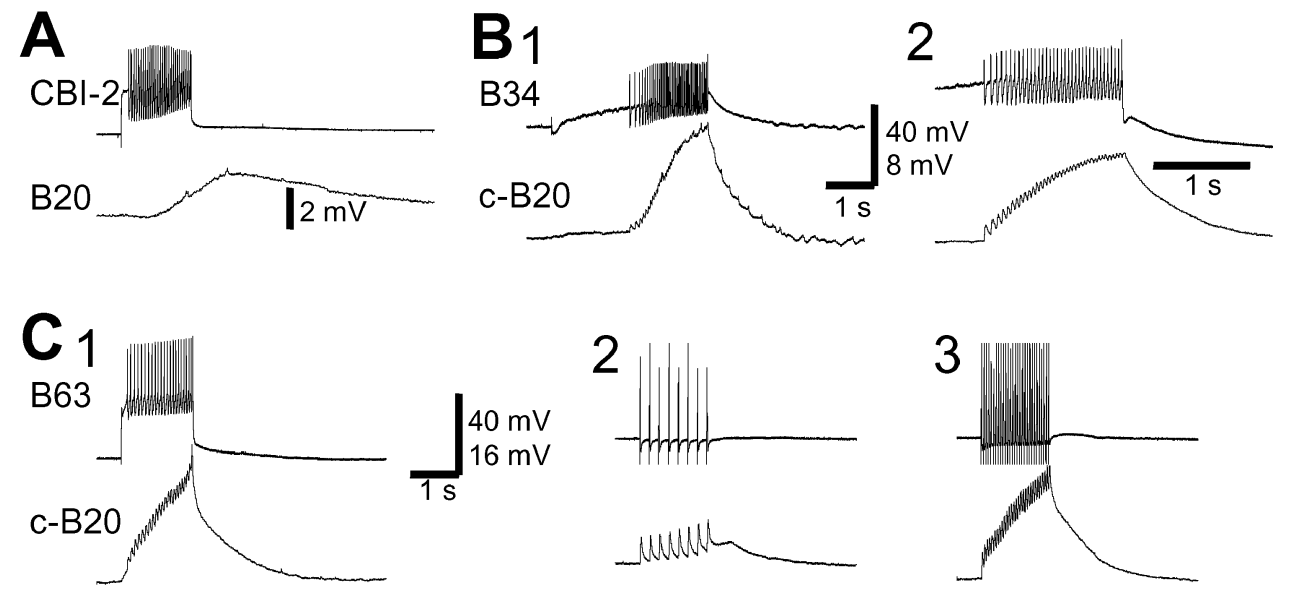

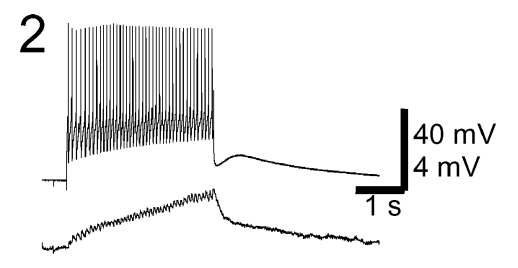

Figure 5. Protraction phase interneuron B20 is synaptically excited by CBI- 2 and by other buccal protraction phase interneurons. $A, \mathrm{CBI}-2$ elicited a long-latency slow EPSP in B20 in high-divalent saline, but unitary EPSPs that followed one-for-one presynaptic spikes were not observed. $B$, B34 elicited EPSPs in c-B20. These EPSPs followed presynaptic spikes one-for-one (1, 2 ), and persisted in high-divalent saline (2), thus suggesting that these connections were monosynaptic. $C, \mathrm{~B} 63$ elicited EPSPs in c-B20 in normal saline (1) and in highdivalent saline $(2,3) . C, 2,3$, B63 was stimulated with brief current pulses at $5 \mathrm{~Hz}$ (2) or $20 \mathrm{~Hz}$ (3). The EPSPs in c-B20 followed presynaptic spikes one-for-one. Notice that the EPSPs from B63 outlasted the fast EPSPs $(C, 2,3)$, thus indicating the presence of a slow component. $D, \mathrm{~B} 65$ elicited EPSPs in c-B20 in normal saline (1) and highdivalent saline (2). The EPSPs followed presynaptic spikes one-for-one.

B4/5 did not fire or fired weakly during ingestive motor programs elicited by CBI-2 (average firing rate, $<8 \mathrm{~Hz} ; n=15$ ) but fired strongly during egestive motor programs (average firing rate, $>10$ $\mathrm{Hz} ; n=8)$.

It has been shown previously (Kabotyanski et al., 1998) that in isolated buccal ganglia, hyperpolarization of a single B4/5 during egestive motor programs increased the firing of B8 during retraction. This suggested that weak firing of B8 during the retraction phase of egestive programs may in part be attributable to the strong firing of B4/5. Because B4/5 is weakly active during the CBI-2-elicited ingestive motor program, in which B8 and B16 fire strongly during retraction (Figs. 1, 4), we investigated whether weak firing of $\mathrm{B} 4 / 5$ is required to enable the strong firing of radula closure motoneurons during the retraction phase of ingestive motor programs. A single B4/5 was stimulated by current injection during the retraction phase of CBI-2-elicited ingestive motor programs. When B4/5 was activated, the activity of the ipsilateral B8 $(n=4)$ and B16 $(n=3)$ was completely suppressed (Fig. $4 A, 2, B, 2)$. This indicates that strong $\mathrm{B} 4 / 5$ activity can override the excitation that $\mathrm{B} 8$ and $\mathrm{B} 16$ receive during the retraction phase of CBI-2-elicited ingestive motor programs. Taken together, B4/5 contributes significantly to egestive motor programs by suppressing B8 and B16 firing during retraction.

\section{Synaptic connections of B20 within the feeding CPG}

We analyzed the pattern of synaptic inputs and outputs of B20 within the feeding CPG to understand how B20 is recruited specifically into the protraction phase of CBI-2-elicited motor programs. We found that B20 is an important element of the feeding CPG as it makes extensive synaptic connections with other CPG elements.

Because B20 is active in CBI-2-elicited motor programs, we first sought to determine whether CBI-2 directly activates B20. Teyke et al. (1993) reported that CBI-2 did not elicit short-latency EPSPs in B20. Our results agree. However, we found that a burst of CBI-2 action potentials induced a slow depolarization in B20
(Fig. 5A). Because this depolarization persisted in high-divalent saline, this synaptic response may be monosynaptic.

The putative monosynaptic excitation that CBI-2 evoked in B20 was small and therefore unlikely to be solely for responsible for activation of B20 by CBI-2 stimulation. We found, however, that other protraction phase interneurons, which are directly activated by CBI-2 (Hurwitz et al., 1997, 2000; Sanchez and Kirk, 2000) (Fig. 12) during feeding motor programs, constitute a significant source of excitatory input to B20. Specifically, B34 elicited one-for-one EPSPs in the contralateral B20 (c-B20) (Fig. $5 B, 1)$. These EPSPs persisted in high-divalent saline that raised the spike threshold and suppressed polysynaptic connections (Fig. $5 B, 2)$. Unitary EPSPs from B34 to c-B20 ranged from 0.7 to 1.4

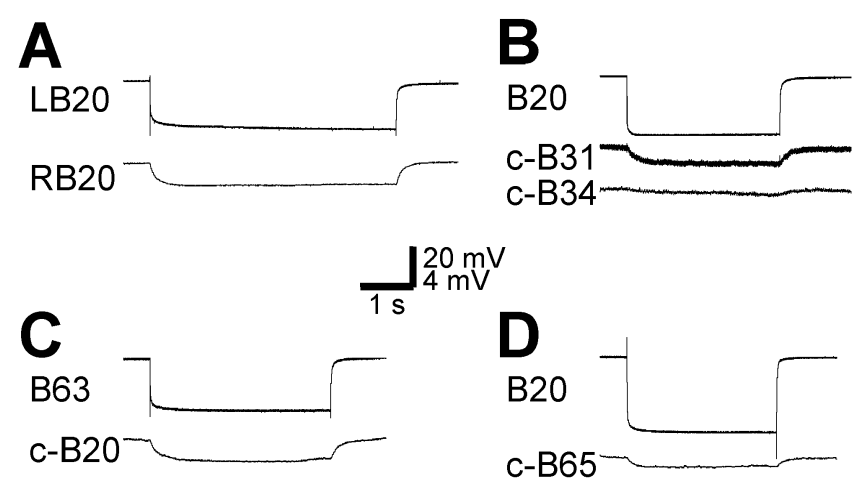

Figure 6. Electrical coupling between B20 and its contralateral homolog and other buccal protraction phase neurons. $A$, The bilaterally symmetrical neurons left $\mathrm{B} 20(L B 20)$ and right $\mathrm{B} 20(R B 20)$ are electrically coupled. $B, \mathrm{~B} 20$ is electrically coupled to the contralateral B31 (c-B31). The hyperpolarization in the contralateral B34 (c-B34) was very small, barely visible, suggesting that there was very weak electrical coupling between B20 and c-B34. $C, D, \mathrm{~B} 20$ is electrically coupled to B63 $(C)$ and B65 $(D)$ contralaterally. $A-C$, Recordings were from high-divalent saline. $D$, Recordings were made in ASW. 

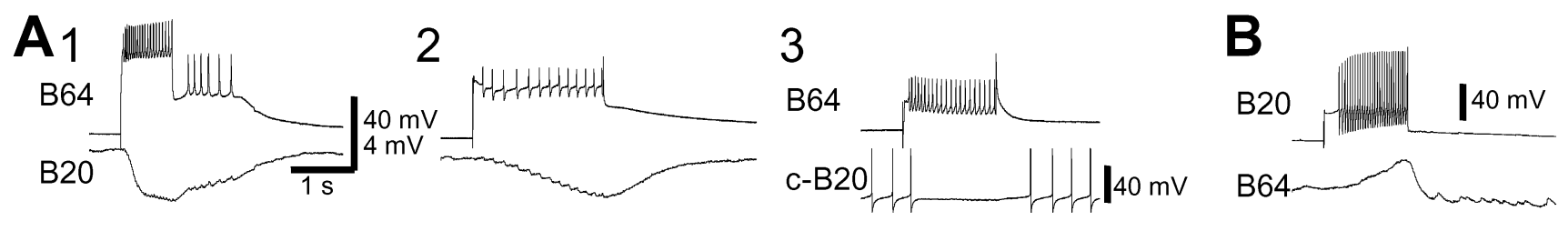

Figure 7. Synaptic connections of B20 with the retraction phase interneuron B64. A, B64 elicited IPSPs in B20 in normal saline (1). These IPSPs persisted in high-divalent saline (2). The IPSPs in B20 followed B64 presynaptic spikes one-for-one. $A$, 3, Inhibitory connections from B64 were functional, because B64 suppressed the firing of c-B20 in normal saline. B20 is not spontaneously active; therefore, we elicited spiking in B20 by a constant intracellular current injection. $B$, Neuron B20 elicited a mixed response (early excitation followed by slow inhibition) in B64 in normal saline. This response is probably polysynaptic, because it was not present in high-divalent saline (data not shown).
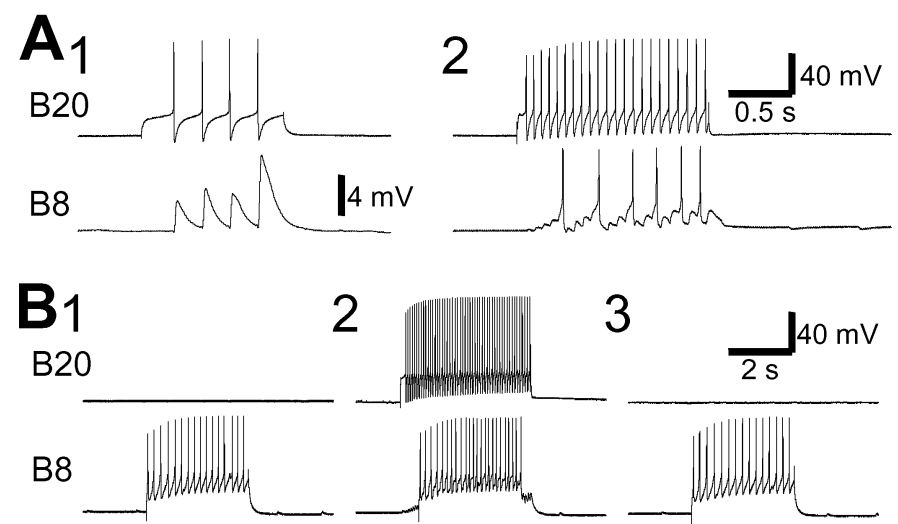

Figure 8. $\quad$ B20 excites the radula-closing motoneuron B8. A, B20-elicited EPSPs in B8 followed B20 spikes one-for-one. B8 was hyperpolarized by $10 \mathrm{mV}(1)$. When B8 was at its resting potential (2), firing of B20 induced B8 firing. $B$, B20 enhanced the excitability of neuron B8. Current test pulses in B8 ( $3 \mathrm{sec}$ duration) were applied every $30 \mathrm{sec}$ to induce regular firing in B8 (16 spikes in 1, 15 spikes in 3). When B20 was fired (2), B8 fired a larger number of spikes (24 spikes).

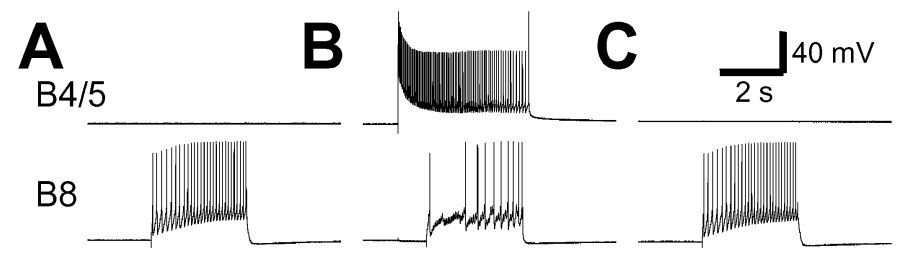

Figure 9. B4/5 reduces the excitability of the radula-closing motoneuron B8. Test pulses in B8 ( $3 \mathrm{sec}$ duration) were applied every $30 \mathrm{sec}$ to induce regular firing in $\mathrm{B} 8$ (28 spikes in $A$ and $C$ ). When $\mathrm{B} 4 / 5$ was fired $(B), \mathrm{B} 8$ fired fewer action potentials (10 spikes).

$\mathrm{mV}$. Like B34, B63 also elicited one-for-one fast EPSPs in the c-B20, and these EPSPs also persisted in high-divalent saline (Fig. $5 C$ ). Unitary EPSPs from B63 to c-B20 were quite large (1.3-2.5 $\mathrm{mV})$. In addition to fast EPSPs, B63 elicited a postsynaptic response in B20 that appeared to consist of a slow depolarizing component that outlasted B63 spiking. Thus, B20 receives monosynaptic EPSPs from neurons B34 and B63.

Like B20, B65 is also a dopaminergic neuron that can drive egestive motor programs. But B65 is active only in some but not all of the CBI-2-elicited egestive motor programs (Kabotyanski et al., 1998; Jing et al., 1999; Jing and Weiss, 2000). B65 elicited fast EPSPs in B20, and these EPSPs appeared to be monosynaptic, because they followed presynaptic spikes one-for-one and persisted in high-divalent saline (Fig. 5D). Unitary EPSPs from B65 to c-B20 were small $(0.35-0.45 \mathrm{mV})$. Reciprocal chemical connections from B20 to c-B34, c-B63, c-B65, and CBI-2 were not observed.

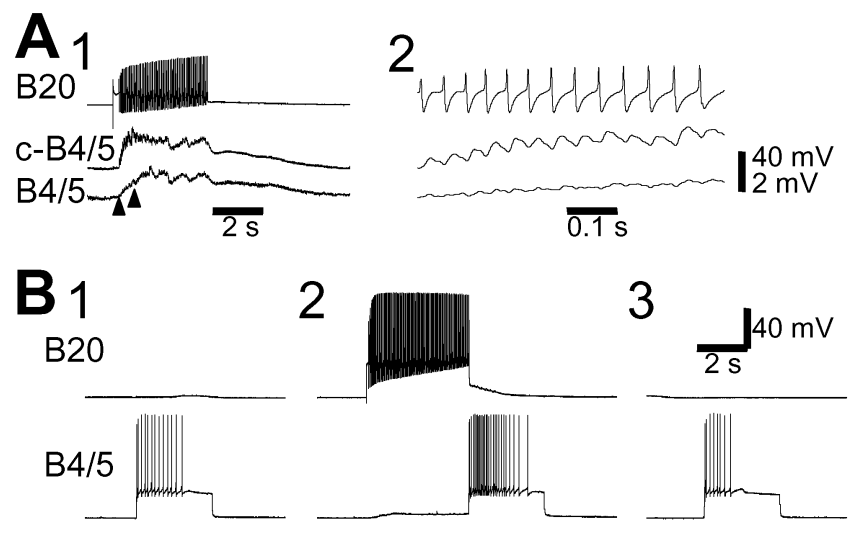

Figure 10. B20 synaptically excites neuron B4/5. A, B20 elicited EPSPs in the contralateral $\mathrm{B} 4 / 5(c-B 4 / 5)$ and ipsilateral $\mathrm{B} 4 / 5$. This excitation had a fast and a slow component (1). The fast EPSPs followed presynaptic spikes one-for-one (2, expanded records of 1 , between arrowheads). This experiment was performed in high-divalent saline. $B, \mathrm{~B} 20$ enhanced the excitability of neuron B4/5. Depolarizing current pulses (3 sec duration) were injected into B4/5 every $30 \mathrm{sec}$ (13 spikes in 1, 8 spikes in 3$)$. When B20 was fired before current was injected into B4/5 (2), B4/5 fired a larger number of spikes (28 spikes).

In addition, B20 was electrically coupled to its contralateral homolog and other protraction phase neurons. Specifically, B20 was electrically coupled to the c-B20 (coupling ratio, $0.097 ; n=5$ ) (Fig. 6A) as well as to the contralateral B31/32 (c-B31/32; coupling ratio, $0.066 ; n=3$ ) (Fig. $6 B$ ). The electrical coupling between $\mathrm{B} 20$ and $\mathrm{B} 31 / 32$ was asymmetric; i.e., the coupling ratio was higher from B31/32 to B20 than from B20 to B31/32 (0.074 vs 0.059). No chemical connections between B20 and the c-B31/32 were observed. There were no significant connections, either chemical or electrical, between B20 and protraction phase motoneurons B61/62. There was a very small, barely noticeable, hyperpolarization in contralateral B34 when B20 was hyperpolarized ( $n=4$; Fig. $6 B$ ), suggesting that there may be some electrical coupling between these two cells, but the coupling was extremely weak. B63 was electrically coupled to the c-B20 (ratio, $0.067 ; n=3$ ) (Fig. 6C). The electrical coupling was asymmetric; i.e., the coupling ratio was higher from B63 to B20 than from B20 to B63 (ratio, 0.072 vs 0.062 ). B65 was electrically coupled to c-B20 just as were B63 and B31, but the coupling strength (ratio, $0.025 ; n=3$ ) (Fig. $6 D$ ) was weaker.

In CBI-2-elicited motor programs, B20 is inhibited in the retraction phase. A major component of inhibition of other protraction phase neurons is attributable to the firing of the retraction phase interneuron B64 (Hurwitz and Susswein, 1996). Similar to all other protraction phase interneurons (Hurwitz et al., 1997), B20 was inhibited by B64. Both ipsilat- 


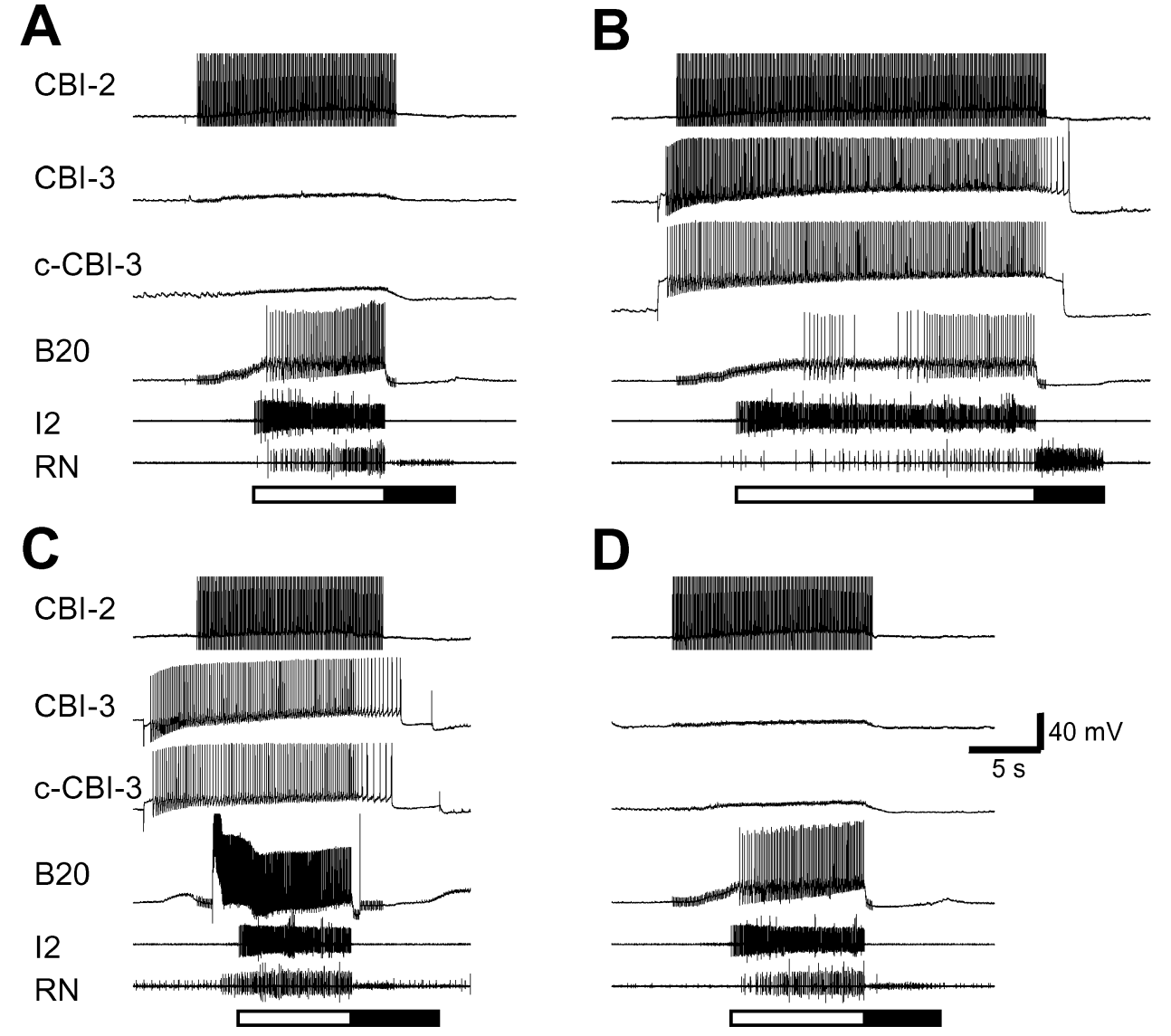

Figure 11. CBI-3 converts CBI-2-elicited egestive programs to ingestive ones by suppressing activity in B20. $A$, Stimulation of CBI-2 with short current pulses at $10 \mathrm{~Hz}$ elicited a single cycle of an egestive motor program, because high-frequency activity in the $\mathrm{RN}$ occurred only during protraction (defined by bursting in the I 2 nerves; open bar). The retraction phase (filled bar) is defined by periods of hyperpolarization of B20 after the protraction phase ended. $B$, DC current stimulation of the ipsilateral CBI-3 and the contralateral CBI-3 (cCBI-3) during CBI-2 stimulation switched the motor program to an ingestive one (high-frequency activity in the RN was now observed during retraction). Coincidentally, B20 activity was suppressed. $C$, The same stimulation was applied on CBI-2 and $\mathrm{CBI}-3$ s as in $B$, but in addition, B20 was fired strongly by DC current injection. The motor program reverted to an egestive mode. $D$, Another cycle of an egestive motor program was elicited by CBI-2 stimulation after that shown in $C$. This cycle of the motor program was similar to the cycle shown in $A$. eral and contralateral B64s elicited IPSPs in B20, and the IPSPs followed presynaptic spikes one-for-one and persisted in high-divalent saline (Fig. $7 A$ ), suggesting that this connection is monosynaptic. These IPSPs are functionally effective because activity of B64 suppresses B20 firing (Fig. 7A, 3). We also found evidence for connections from B20 to B64. The connections from B20 to B64 were complex and variable among different preparations. Sometimes, B20 elicited an early depolarization that was followed by a late hyperpolarization in B64 (Fig. 7B). At other times, B20 elicited an early hyperpolarization that was followed by a late depolarization (data not shown). High-divalent saline eliminated nearly all of these responses, suggesting that these connections were probably polysynaptic.

In summary, activity of B20 during the protraction phase of CBI-2-elicited motor programs appears to be promoted, in large part, by chemical or electrical excitation, or both, from protraction phase motoneurons and interneurons B31/32, B34, and B63, which are known to be active during CBI-2 motor programs (Hurwitz et al., 1997, 2000) (Fig. 12). To a lesser degree, excitatory inputs from CBI-2 and sometimes B65 also contribute to the activation of B20. During retraction, B20 activity is suppressed primarily by B64.

\section{Control of the radula closure motoneurons B8 and B16 by $B 20$ and B4/5}

Because egestive and ingestive motor programs differ in the phase in which the radula closes with respect to protraction-retraction, and B20 and B4/5 are preferentially active during egestive programs, we reasoned that one of the primary functions of B20 and $\mathrm{B} 4 / 5$ is to control the phase in which radula closure occurs (compare Figs. 3, 4). Monosynaptic connections that B20 and B4/5 make with radula closure motoneurons have already been described. It was found that B20 excites B8 and B16 (Teyke et al., 1993), and B4/5 inhibits both B8 (Gardner, 1971, 1977) and B16 (Cohen et al., 1978). To further assess the role of B20 and B4/5 in mediating the egestive motor program, we examined the functional significance of these synaptic connections.

We confirmed that B20 monosynaptically excited B8 (Fig. 8A). Unfacilitated unitary EPSPs from B20 to B8 were $0.5-3.5 \mathrm{mV}$. This EPSP facilitated significantly and could become as large as $10 \mathrm{mV}$ when B20 was fired at $5-15 \mathrm{~Hz}$. At resting potential, B8 frequently fired action potentials when B20 was stimulated at 10-20 Hz (Fig. 8A, 2). In fact, as shown in Figure 2, when B20 was driven to induce motor programs, the activity in RN (i.e., B8) typically preceded that of the $\mathrm{I} 2$ nerve, suggesting that B20 provides stronger excitation to radula closure motoneurons than to radula protraction motoneurons. In addition, B20 also strongly increased the excitability of B8 $(n=4$; Fig. $8 B)$ and B16 (data not shown). In contrast, B4/5 decreased the excitability of B8. When B4/5 was costimulated together with B8, B8 firing was markedly reduced compared with its firing without costimulation of B4/5 $(n=4$; Fig. 9).

Both B20 and B4/5 are preferentially active in egestive programs, and they act concurrently to mediate the phasing of radula closure so that it is appropriate for egestive motor programs. Because the joint action of B20 and B4/5 is important for generating egestive programs, we sought to determine how these neurons interact with each other. We found that B20 makes monosynaptic chemical connections to B4/5. B20 monosynaptically excited both the ipsilateral and contralateral B4/5, with both fast 


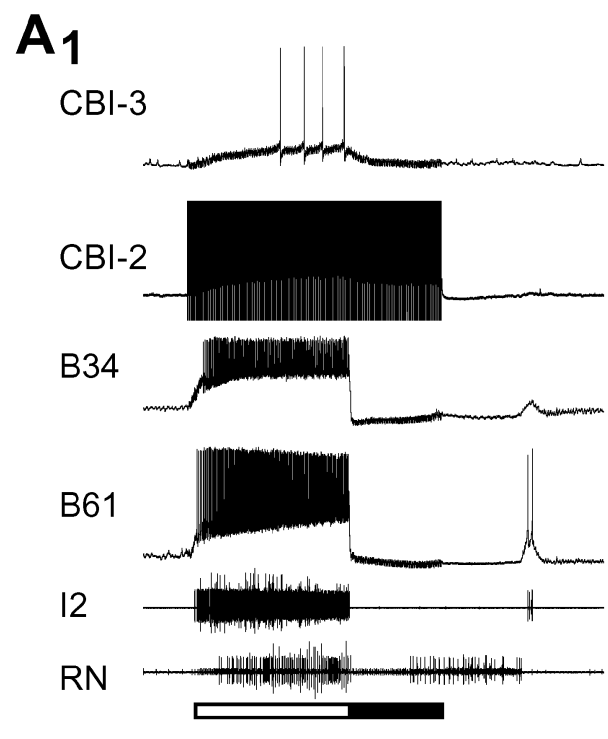

2

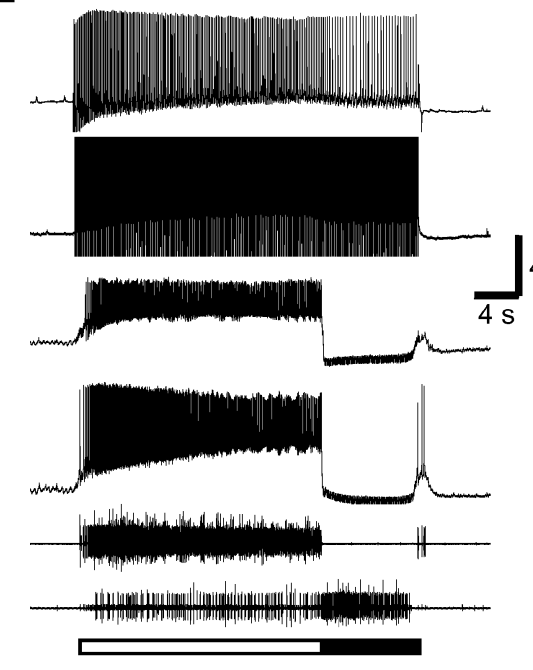

2

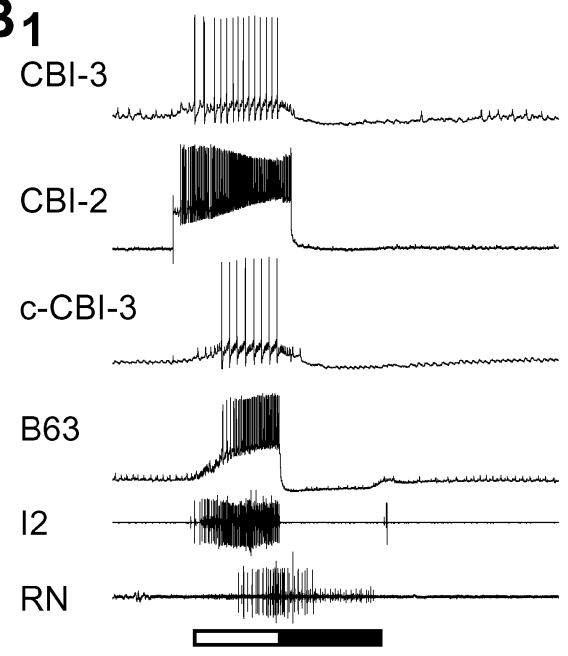

3

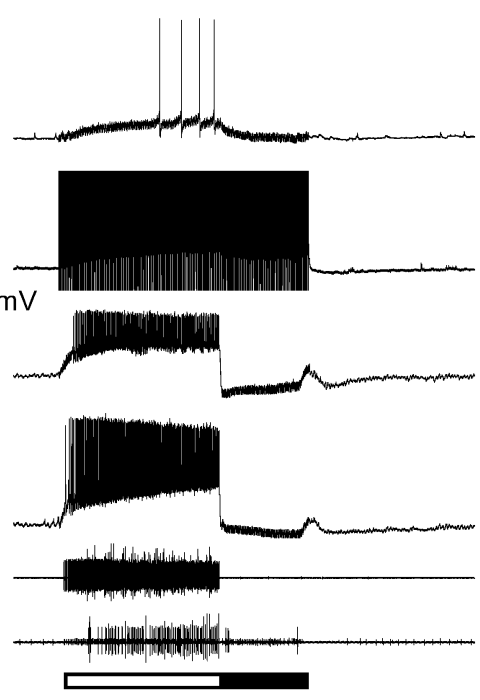

3

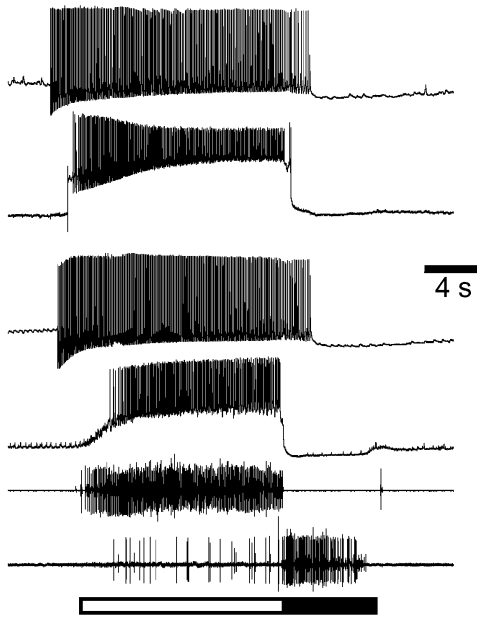

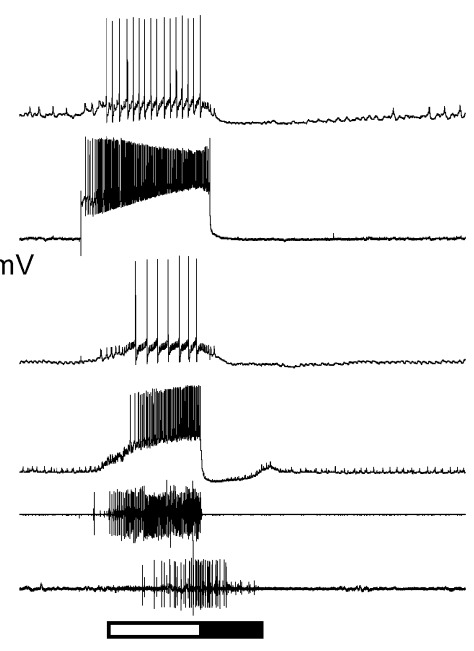

Figure 12. Activity of the protraction phase interneuron $\mathrm{B} 34(A)$ and $\mathrm{B} 63(B)$ during single cycles of CBI-2-elicited motor programs. $A$, CBI-2 was stimulated by a brief current pulse $(10 \mathrm{msec})$ at $15 \mathrm{~Hz}$. When firing of CBI-3 was not experimentally manipulated, motor programs induced by CBI-2 stimulation were egestive (1,3), because the high-frequency activity in RN occurred during protraction (open bar), not during retraction ( filled bar). When CBI-3 was depolarized, the motor program induced by CBI-2 became ingestive (2), because the high-frequency activity in RN now occurred during retraction. In both types of programs, B34 and the protraction phase motoneuron B61 were strongly active. $B$, CBI-2 was stimulated by DC current. $B, 1,3$, Without controlled firing of CBI-3, motor programs induced by CBI-2 were egestive in 1; i.e., RN activity primarily occurred during the protraction phase (open bar); but they were mixed in 3; i.e., RN activity occurred in both protraction and retraction phases (filled bar). $B$, 2, When ipsilateral CBI-3 and contralateral CBI-3 (c-CBI-3) were depolarized, the motor program induced by CBI-2 was ingestive. In all types of motor programs, B63 was strongly active.

and slow EPSPs that were present in high-divalent saline (Fig. $10 A)$. Fast EPSPs followed presynaptic spikes one-for-one and were larger and were more easily resolved as unitary EPSPs in the contralateral B4/5 ( $n=6$; Fig. $10 A, 2)$. This excitatory connection appeared to be functional, because B20 enhanced the excitability of B4/5 ( $n=4$; Fig. $10 B)$. In these experiments, test pulses in B4/5 were applied not during but after B20 stimulation. This paradigm was used to simulate normal firing relationships between B20 and B4/5. During normal feeding programs, B20 fires during the protraction phase, whereas B4/5 fires during the retraction phase, which follows the protraction phase. B4/5 elicited weak depolarization in B20, but this response is probably polysynaptic, because it disappeared in high-divalent saline (data not shown).

\section{CBI-3 converts motor programs by suppressing B20 and B4/5 activity}

In the experiments described above, we identified the buccal CPG neurons that are critical for CBI-2-elicited egestive motor programs (i.e., B20 and B4/5). In the following studies, we investigated how $\mathrm{CBI}-3$ converts egestive motor programs to ingestive ones. Because B20 is central to CBI-2-elicited egestive motor programs, we hypothesized that CBI-3 might switch motor programs, at least in part, by suppressing activity in B20. The role of B20 in motor program switching is illustrated in Figure $11(n=$ 4). Stimulation of CBI-2 induced strong spike activity in B20 (average firing rate, $\sim 10 \mathrm{~Hz}$ ), and the motor program was eges- 
tive (Fig. 11A,D). When CBI-3 was coactivated with CBI-2, egestive motor programs were converted to ingestive programs (i.e., RN activity primarily occurred during retraction rather than protraction). Coincidentally, B20 activity was dramatically reduced (average firing rate, $\sim 4 \mathrm{~Hz}$ ) (Fig. $11 B$ ). However, when current was also injected into B20 so that it fired together with CBI-3 and CBI-2, the motor program remained egestive (Fig. $11 C$ ), suggesting that CBI-3 switches programs by suppressing B20 activity. Elsewhere (Morgan et al., 2001), it has been shown that B4/5 activity was markedly reduced when CBI-3 switched CBI-2-elicited egestive motor programs into ingestive ones.

We examined whether other buccal neurons may also play a role in the CBI-3-induced switch. We found that protraction phase interneurons B34 and B63 are active in both types of motor programs (Fig. 12). In addition, we have shown that the retraction phase interneuron B64 (Hurwitz and Susswein, 1996) is also active during both types of CBI-2-elicited motor programs (Jing et al., 1999). Our results suggest that these neurons probably do not play a significant role in program switching. Rather, their primary functions may be to mediate the basic protractionretraction sequence that is common among all types of feedingrelated behaviors. In another study (Hurwitz et al., 1997), B63 and B34 were shown to provide prominent excitation to protraction motoneurons B31/32 and B61/62. Other buccal elements, B65 (Kabotyanski et al., 1998) and B51 (Plummer and Kirk, 1990; Evans and Cropper, 1998), are either inactive (B51) or variably active (B65) during the CBI-2-elicited motor program (Jing et al., 1999; cf. Jing and Weiss, 2000) and thus are not likely to play a major role in switching between these types of motor programs. Note that in previous studies in which isolated buccal ganglia were used and motor programs were either active spontaneously or elicited by nerve stimulation, it was shown that B34 (Hurwitz et al., 1997) and B51 (Nargeot et al., 1999) contribute specifically to egestive or ingestive motor programs, respectively. Because Aplysia produces various forms of ingestive and egestive behaviors, it is possible that B34 and B51 may contribute to other types of switching.

\section{Direct suppression of B20 and B4/5 activity by $\mathrm{CBI}-3$ and its peptide, APGWamide}

Because egestive motor programs elicited by CBI-2 are converted into ingestive programs by CBI-3 activity, and this program switch is accompanied by suppression of activity in the switch neurons B20 and B4/5, we examined synaptic connections from CBI-3 to neurons B20 and B4/5.

One significant finding of this study is that CBI-3 monosynaptically inhibits B20 and suppresses B20 firing (Fig. 13). The unitary IPSPs from CBI-3 to B20 were typically indistinguishable when B20 was held at resting potential but became apparent when B20 was depolarized (Fig. 13B). The IPSPs were facilitating and present in both normal and high-divalent saline. CBI-3 also reduced the excitability of B20. In normal saline, current injections (3 sec duration) into B20 often elicited buccal motor programs (compare Fig. 2), thus making it nearly impossible to obtain a constant firing rate of B20 with these test pulses. Therefore, we conducted these experiments in high-divalent saline. In these experiments, B20 spiking was reduced in a frequency-dependent manner when CBI-3 was costimulated with B20 ( $n=3$; Fig. $14 A)$.

CBI-3 also inhibited B4/5. Rosen et al. (1991) found that CBI-3 induced fast IPSPs in B4/5, and these IPSPs followed presynaptic spikes one-for-one. During normal feeding motor programs, CBI-3 and B4/5 activity are out of phase (i.e., CBI-3 fires in

\section{A Normal saline}

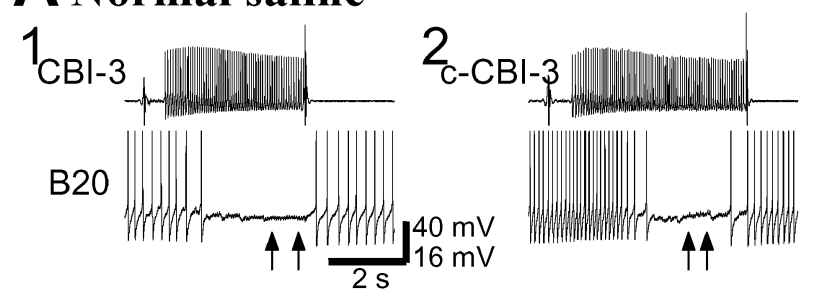

3

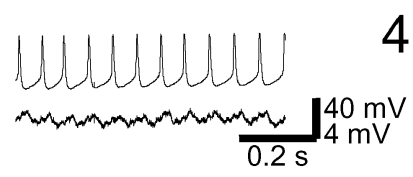

4

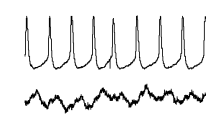

B HD

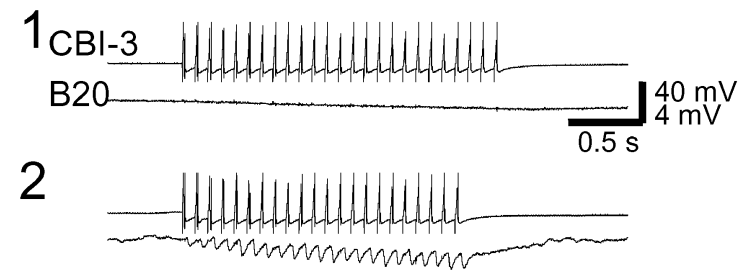

Figure 13. CBI-3 monosynaptically inhibits B20. A, Both the ipsilateral CBI-3 and the contralateral CBI-3 (c-CBI-3) suppressed B20 firing $(1,2)$ in normal saline. B20 is not spontaneously active; therefore, its spiking was induced by a small DC current injection. The IPSPs elicited by CBI-3 followed presynaptic spikes one-for-one $(3,4) . A, 3$ and 4 are expanded records of 1 and 2 (between arrows) respectively. Spikes in B20 were clipped. $B$, In high-divalent saline $(H D)$, stimulation of CBI-3 with brief current pulses at $12 \mathrm{~Hz}$ did not induce visible IPSPs when B20 was at its resting potential (1), but it induced one-for-one facilitating IPSPs in B20 when B20 was depolarized by $20 \mathrm{mV}$ (2). Note that in B, 2, B20 was not spiking even with $20 \mathrm{mV}$ depolarization, because high-divalent saline raised the spike threshold of $\mathrm{B} 20$.

protraction, whereas B4/5 fires in retraction), which makes the fast IPSPs functionally ineffective. Thus, we tested effects of CBI-3 on B4/5 excitability in a different way than we did with B20. CBI-3 was fired before the $3 \mathrm{sec}$ test pulses were applied to B4/5, rather than together with $\mathrm{B} 4 / 5$. Under these conditions, the slow action of CBI-3 on B4/5 spiking can be revealed. Indeed, CBI-3 reduced $\mathrm{B} 4 / 5$ spiking in a frequency-dependent manner $(n=8$; Fig. 14B). This slow inhibitory effect of CBI-3 on B4/5 also persisted in high-divalent saline (data not shown), suggesting that the inhibition is monosynaptic. Thus, CBI-3-induced reduction of B4/5 excitability is likely to have functionally relevant consequences during normal motor programs.

It has been shown previously that CBI-3 contains the neuropeptide APGWamide, and like CBI-3, APGWamide can convert CBI-2-elicited egestive motor programs to ingestive ones (Morgan et al., 2001). In Figure 15, we show that, like CBI-3, APGWamide also suppressed the excitability of B20 $(n=5)$ and $\mathrm{B} 4 / 5(n=5)$. This effect was concentrationdependent, with $10^{-5}$ M APGWamide completely eliminated any firing of these cells. This suggested that APGWamide may also act on B20 and B4/5 to switch motor programs.

CBI-3 is able to reduce the excitability of B4/5 in a delayed manner (i.e., after the firing of CBI-3 has ceased) (Fig. 14B). Because APGWamide contained in CBI-3 also suppressed B4/5 excitability (Fig. 15B), there is a distinct possibility that this delayed inhibition is mediated by APGWamide. This possibility was examined in a series of occlusion experiments in 

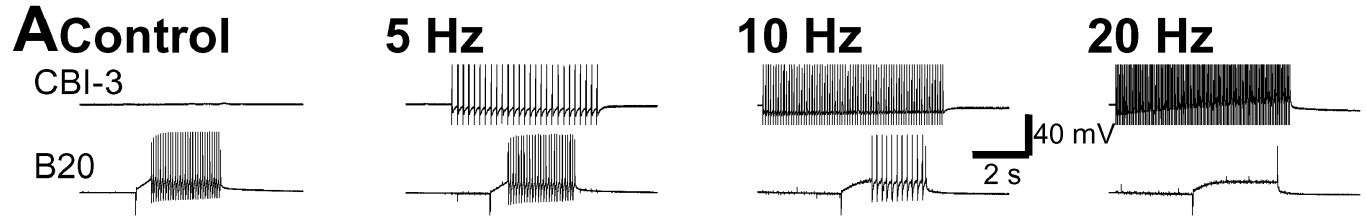

Recovery
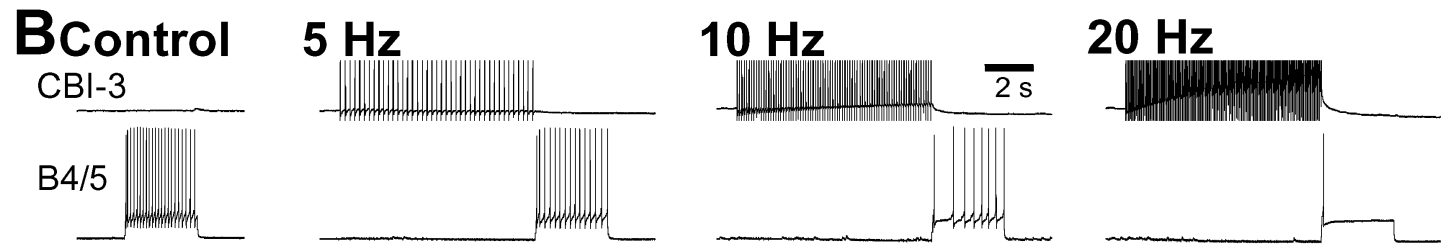

Recovery

Figure 14. $\quad$ CBI-3 reduces the excitability of B20 and B4/5 in a frequency-dependent manner. Current pulses ( 3 sec duration) were injected into B20 $(A)$ and B4/5 $(B)$ every $30 \mathrm{sec}$. CBI-3 was stimulated by brief current pulses at 5,10 , or $20 \mathrm{~Hz} . A$, CBI-3 was stimulated before and during the injection of current pulses into B20. B20 firing was reduced in a frequency-dependent manner (from left to right, 29, 26, 11, 0 , and 28 spikes). Recordings were obtained from high-divalent saline. $B$, CBI-3 was stimulated for $8 \mathrm{sec}$ before injection of current pulses into B4/5. B4/5 firing was also reduced in a frequency-dependent manner (from left to right, 22, 15, 8, 1, and 20 spikes). Recordings were obtained from normal saline.

Figure 15. APGWamide decreases the excitability of B20 and B4/5 in a concentration-dependent manner. Depolarizing current pulses ( $3 \mathrm{sec}$ duration) were injected into B20 $(A)$ and B4/5 $(B)$ every 60 sec. APGWamide was applied in ascending concentrations (from $10^{-7}$ to $10^{-5} \mathrm{M}$ ). $A$, Examples from experiments that were performed in normal saline (1) and in high-divalent saline (2). The application of APGWamide reduced the excitability of B20 in a concentration-dependent manner (from left to right, 40, 24, 12, 0, and 33 spikes in $1 ; 28,22,12,0$, and 19 spikes in 2). B20 spiking showed almost complete recovery in normal saline (1) and only partial recovery in high-divalent saline (2)
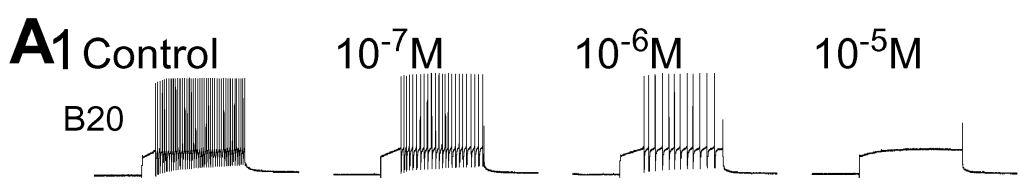

Wash
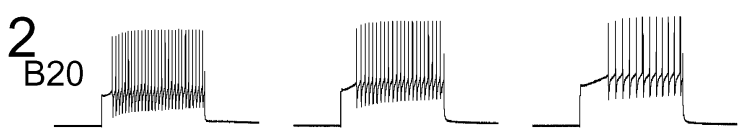

B
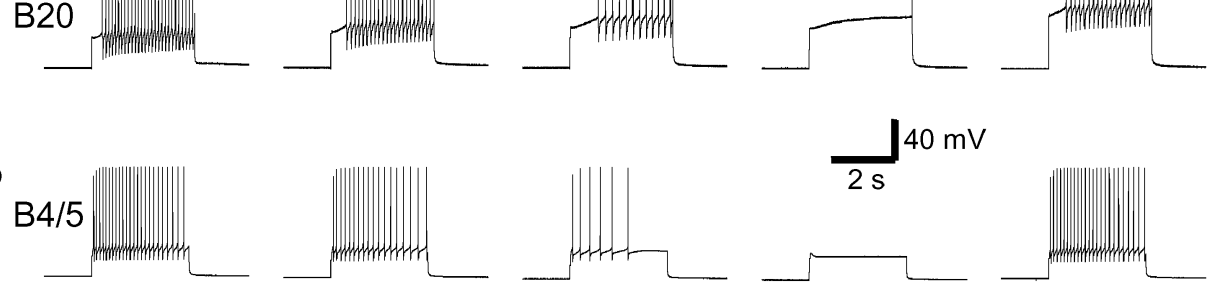
was reduced by APGWamide in a concentration-dependent manner (from left to right, 24, 18, 6, 0, and 24 spikes). B4/5 spiking recovered completely after peptide washout. Experiments were performed in normal saline.

which we sought to determine whether APGWamide perfusion blocked the ability of CBI-3 to inhibit B4/5 ( $n=4$; Fig. 16). The excitability of B4/5 was tested by injecting depolarizing current pulses that elicited $\sim 20$ action potentials in $\mathrm{B} 4 / 5$. When CBI-3 was fired for $8 \mathrm{sec}$ at $10 \mathrm{~Hz}$ before injecting current pulses into B4/5, the firing of B4/5 was almost completely suppressed. When the preparation was perfused with $10^{-4} \mathrm{M}$ APGWamide, the current pulses that induced firing of B4/5 no longer did so, because APGWamide suppressed the excitability of B4/5 (Fig. 15B). The size of the current pulse injected into B4/5 was therefore adjusted to again elicit $\sim 20$ action potentials. Under these conditions, firing of CBI-3 no longer suppressed the firing of B4/5. Indeed, a small increase in B4/5 activity was observed (Fig. 16 $A$ ). On washout of APGWamide, the inhibitory action of CBI-3 was almost completely restored. In control saline and washout of APGWamide, CBI-3 on average reduced the B4/5 firing by 94 and $80 \%$ respectively (percent change is expressed as change of the number of spikes in B4/5 by CBI-3 over the average of control and recovery), whereas during bath application of $10^{-4}$ M APGWamide, CBI-3 somewhat increased the firing of B4/5. Repeated measures ANOVA of three groups, control, APGWamide, and wash, showed significant differences among these groups $\left(F_{(2,3)}\right.$ $=84.201 ; p<0.0001)$, and a Bonferroni multiple comparisons test of different group pairs showed that the APGWamide group was significantly different from the control $(p<0.001)$ and wash $(p<0.001)$ groups, whereas the control and wash groups showed no significant differences $(p>0.05)$. These experiments suggested that the slow inhibitory action of CBI-3 on B4/5 may be mediated by APGWamide that is released by CBI-3.

\section{DISCUSSION}

\section{Neural mechanisms of switching between ingestive and egestive motor programs in Aplysia}

We investigated neuronal mechanisms that underlie switching between ingestive and egestive motor programs in Aplysia. Buccal motor programs were elicited by stimulation of a command-like higher-order neuron, CBI-2, that was shown to elicit both ingestive and egestive motor programs (Rosen et al., 1991, 1997; Church and Lloyd, 1994; Sanchez and Kirk, 2000; Morgan et al., 2001). Another study (Morgan et al. 2001) indicated that the nature of motor programs elicited by $\mathrm{CBI}-2$ is influenced by coactivation of interneuron CBI-3. CBI-3 can convert CBI-2- 

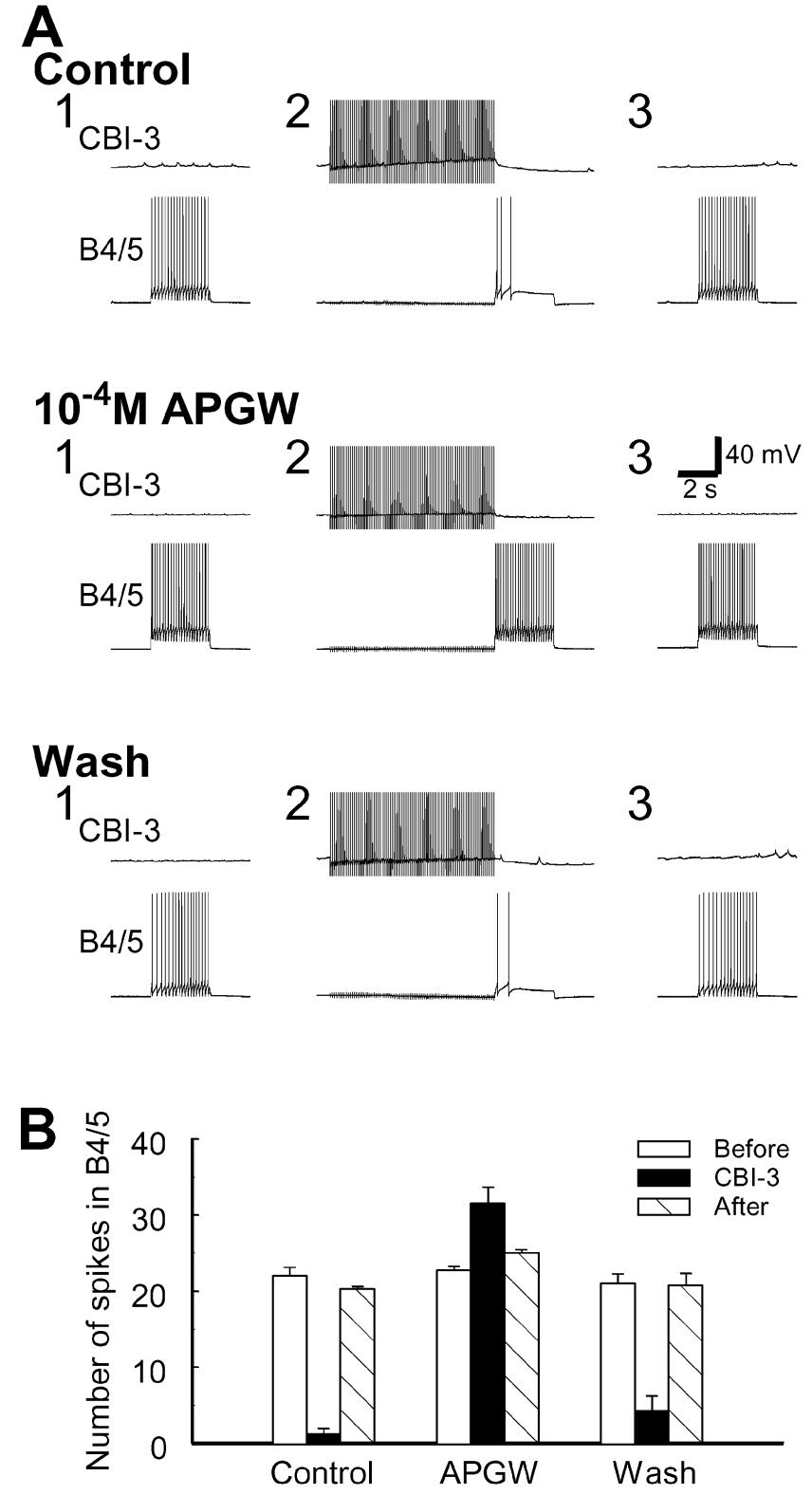

Figure 16. APGWamide occludes the CBI-3-induced inhibition of B4/5 excitability. $A$, Test pulses in $\mathrm{B} 4 / 5$ (3 sec duration) were applied every 30 sec to induce regular firing in B4/5. CBI-3 was stimulated by brief current pulses at $10 \mathrm{~Hz}$ for $8 \mathrm{sec}$ before injection of current pulses into B4/5. Both in control conditions and after APGWamide washout, CBI-3 suppressed B4/5 spiking (compare Fig. 14B). However, in the presence of $10^{-4} \mathrm{M}$ APGWamide, CBI-3 no longer suppressed B4/5 spiking. In fact, B4/5 activity was increased. Note that APGWamide by itself also reduced B4/5 excitability (Fig. 15B). The size of current pulses injected into B4/5 during bath application of APGWamide was increased to induce B4/5 firing comparable with that in control. $B$, Plot of group data of the effect of APGWamide on CBI-3 inhibition of B4/5 excitability $(n=4)$. Error bars indicate SEM.

elicited egestive programs into ingestive ones. CBI-2 and CBI-3 are activated by food stimuli, but CBI-3 is inhibited by stretching of the esophagus, which also elicits egestion. Thus, motor programs elicited by stimulation of CBI-2 alone or in combination with CBI-3 are likely to be behaviorally relevant.

Our study suggests that the constancy of protraction-retraction phasing in ingestive and egestive motor programs elicited by CBI-2 is implemented by the same CPG elements. Specifically, the interneurons B34 and B63, which excite the protraction motoneurons B31/32 and B61/62 (Susswein and Byrne, 1988; Hurwitz et al., 1996, 1997), are activated first in both types of motor programs. Similarly, the interneuron B64, which inhibits protraction phase neurons (Hurwitz and Susswein, 1996), is subsequently activated in both ingestive and egestive programs (Jing et al., 1999).

However, the phasing of radula closure motoneurons (B8, B16) is altered relative to the protraction-retraction sequence, so that in egestion closure occurs during protraction, whereas in ingestion it occurs during retraction (Cropper et al., 1990; Morton and Chiel, 1993a,b; Church and Lloyd, 1994). Thus, the timing of radula closure is not likely to be determined by the activity of the above protraction and retraction interneurons. Indeed, we found that a separate group of buccal neurons (B20 and B4/5) is responsible for the expression of egestive rather than ingestive programs. B20, which is active during protraction, excites radula closure motoneurons, and B4/5, which is active during retraction, inhibits these motoneurons. Thus, the combined activity of B20 and B4/5 enables expression of egestive motor programs. Consistently, B20 and B4/5 are strongly activated during CBI-2-elicited egestive programs but are either not active or only weakly active during ingestion. B4/5 has already been shown to be more active during egestion than during ingestion in both isolated and intact preparations (Church and Lloyd, 1994; Warman and Chiel, 1995; Morgan et al., 2001). In addition, experimental manipulations of the activity of both neurons alter the characteristics of motor programs in a manner consistent with their roles as mediators of egestive programs. Thus, firing of B20 can convert CBI-2-elicited ingestive programs into egestive ones, even when CBI-3 fires strongly. Hyperpolarization of B20 switches CBI-2-elicited egestive programs to ingestive ones. It has been shown (Kabotyanski et al., 1998) that hyperpolarization of B4/5 enhances B8 firing during the retraction phase in spontaneous or B31/32-induced egestion. We now show that firing of B4/5 during the retraction phase of CBI-2-elicited ingestive motor programs eliminates firing of B8 and B16 during retraction.

Because we have found that B20 and B4/5 mediate egestion, we were able to elucidate at the circuit level the ability of CBI-3 to convert CBI-2-elicited egestive programs into ingestive ones. The CBI-3-implemented program switch can be accounted for by the inhibition of B20 and B4/5 by CBI-3 (Fig. 17). Specifically, in the absence of CBI-3 activity, CBI-2 activates B20 through direct and indirect excitation. In turn, through slow synaptic excitation, B20 modulates B4/5 so that the excitatory inputs, which B4/5 receives during retraction, induce stronger firing of B4/5. Consequently, the program is egestive. However, when CBI-3 is coactivated with $\mathrm{CBI}-2, \mathrm{CBI}-3$ inhibits $\mathrm{B} 20$ and in turn removes the excitation of B4/5 by B20. Moreover, CBI-3 produces a slow inhibition of B4/5 and thereby reduces the excitability of B4/5 during retraction. Because CBI-2-elicited egestive programs became ingestive when B20 was hyperpolarized, the action of CBI-3 to functionally remove B20 and B4/5 from the circuit suffices to switch CBI-2-elicited egestive programs to ingestive ones.

Our findings suggest a model that incorporates the critical features of the Aplysia feeding circuit that contribute to motor program switching (Fig. 17). First, the neural elements for the common protraction-retraction sequence are used in both ingestion and egestion. These elements include the command-like neuron CBI-2 as well as buccal protraction phase interneurons B34 and B63 and the retraction phase interneuron B64. Second, specific types of motor programs (i.e., either ingestion or eges- 


\section{A. EGESTION}

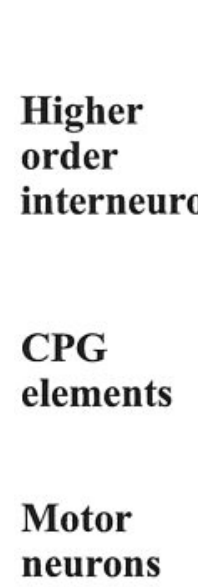

\section{P-GROUP}

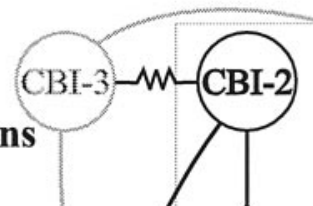

$\vdots$

R-GROUP

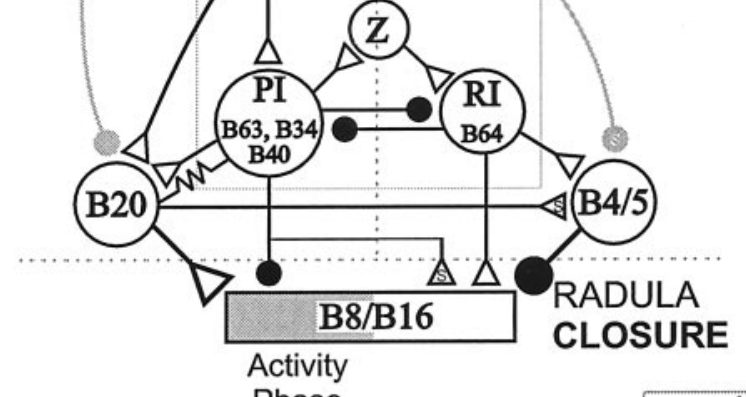

Phase

\section{B. INGESTION}

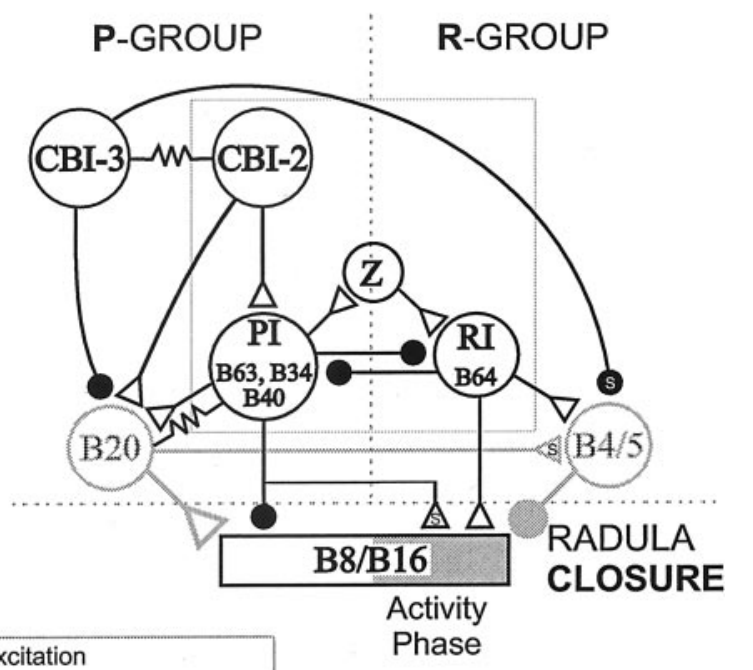

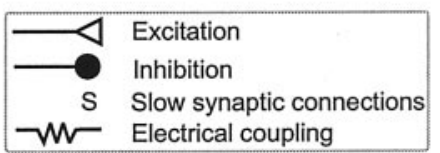

Figure 17. Functional configurations of the Aplysia feeding CPG in the egestive $(A)$ and ingestive $(B)$ modes. Each cycle of buccal motor programs consists of two phases: radula protraction $(P)$ and retraction $(R)$, which are mediated respectively by protraction phase interneurons $(P I)$ [i.e., B34, B63 (Hurwitz et al., 1997), and B40] and retraction phase interneurons (RI) [e.g., B64 (Hurwitz and Susswein, 1996)]. B40 is a newly identified buccal-cerebral interneuron (Jing and Weiss, 2001). The protraction phase is initiated by CBI-2, which drives PIs. Mutual inhibition between PIs and RIs ensures that protraction and retraction phases alternate with respect to each other. The switch from protraction to retraction is presumed to be mediated by a hypothesized $z$ cell, which receives excitation from PIs and in turn activates the RIs (Baxter et al., 1997). The main criterion for distinguishing between ingestive and egestive motor programs is the timing of activity in radula closure motoneurons B8 and B16 (Cropper et al., 1990; Morton and Chiel, 1993a,b; Church and Lloyd, 1994). During ingestion, radula closure occurs primarily during retraction (B). During egestion, radula closure occurs during protraction $(A)$. $A$, In the absence of CBI-3 activity, CBI-2 drives B20 through direct and indirect (via PIs) pathways. B20 in turn enhances B4/5 firing. Strong activity in B20 induces B8/B16 firing during protraction; thus the motor programs are egestive. In the protraction phase, the weak inhibitory connections from PIs to B8 are overridden by excitatory actions of B20 (compare Fig. 11C). In the retraction phase, the excitatory connections from RIs and PIs to B8/B16 are overridden by B4/5 (compare Fig. 4A, 2, B, 2). $B$, When CBI-3 is coactive with CBI-2, ingestive programs are generated. Fast and slow inhibitory actions of CBI-3 functionally remove B20 and B4/5 from the circuit. In the absence of excitation from B20 during protraction, fast inhibition of B8 by the PIs suppresses B8 firing. During the retraction phase, the inhibitory input from B4/5 is no longer present; therefore, a combination of slow and fast excitation, originating respectively from the PIs (B34 and B40) and the RIs, induces B8 firing. Thus, B8 and B16 fire during retraction, and the motor programs become ingestive. Note that the inhibitory connection from B64 to B20 is omitted for clarity. Inactive neurons and their synaptic outputs are shown in gray.

tion) are produced by combining these shared elements with specialized elements that control, directly or indirectly, radula closure. For egestion, both the protraction phase interneuron B20 and the retraction phase neuron $\mathrm{B} 4 / 5$ are required to enable firing of $\mathrm{B} 8$ during the protraction phase. To switch to ingestion, CBI-3 suppresses B20 and B4/5. Therefore, a single set of interneurons controls the common protraction-retraction movements regardless of which program is generated, whereas additional elements that control the phase-shifting movements (radula closure) can be rapidly activated or inactivated to generate appropriate behaviors. This efficient, flexible design allows for rapid contextdependent switching.

\section{Comparison with other systems: motor pattern selection strategies}

Motor program switching in Aplysia involves neurons at two levels: CPG elements (B20 and B4/5) and a higher-order interneuron (CBI-3). At the level of the CPG, B20 and B4/5 may be similar to switch neurons described in two other systems. In the crab gill ventilation system, the activity of single switch neurons can be turned on or off by a neural network (either premotor or sensory), thus allowing the CPG to generate two distinct motor patterns (DiCaprio, 1990). In the leech heart, a similar network, named the switch timing oscillator, tonically inhibits two switch interneurons via a persistent leak current to produce alternate inactivation of these two neurons (Calabrese et al., 1995). Unlike Aplysia, the identity of the premotor or sensory networks acting on these switch neurons remains unknown, thus preventing a more detailed comparison.

Higher-order projection neurons of crustacean stomatogastric nervous system (STNS), which are analogous to CBIs, were shown to play a variety of roles in motor pattern selection. These neurons can induce or modulate specific motor patterns. In many cases, these actions involve peptides (Dickinson and Moulins, 1992; Harris-Warrick et al., 1992; Blitz et al., 1999; Wood et al., 2000). These neurons can also construct a new functional network from multiple seemingly independent networks (Meyrand et al., 1994). Outputs of specific projection neurons can be influenced by direct inhibition from other projection neurons (Blitz and Nusbaum, 1997, 1999) or presynaptic inhibition from a CPG element (Coleman et al., 1995; Bartos and Nusbaum, 1997). Our description of CBI-3-induced motoneuronal phase shifting being mediated via inhibition of specific CPG elements complements the above-mentioned strategies that are used by projection neurons to produce various modifications of motor programs.

Motor program switching in Aplysia is most similar to the ingestion-egestion switch in Pleurobranchaea (Croll et al., 1985) 
and to the switch between crustacean types I and II gastric mill programs (Combes et al., 1999a,b). Although we were unable to compare Pleurobranchaea with Aplysia because of lack of detailed information on Pleurobranchaea's CPG, comparison of the lobster gastric mill with Aplysia feeding suggests that the specifics of circuit organization may necessitate the use of different switching mechanisms. Specifically, the switch from egestion to ingestion in Aplysia and from type I to type II programs in lobster are similar in that after the switch, motoneurons that control the protraction-retraction sequence maintain their phase relationship, but radula closure in Aplysia and the lateral teeth closure of lobster switch the phases in which they are active with respect to the protraction-retraction sequence. In both systems, one motor program is elicited by a higher-order neuron, and the switch to another program occurs when an inhibitory interneuron is recruited (Combes et al., 1999a). However, the actions of the inhibitory interneuron differ. In Aplysia, CBI-3 switches off two CPG elements, whereas in lobster the inhibitory interneuron, through its phasic inhibition, directly shifts the phases in which the motoneurons are active. This direct phase shifting in the lobster is effective because these motoneurons also function as CPG elements. In Aplysia, a separate layer of CPG elements is intercalated between higher-order neurons and motoneurons (Fig. 17). Thus, the phasing of radula closure during egestion is determined by two CPG elements, each of which is active in different phases of the programs. CBI-3, which is only active in protraction phase, uses fast and slow inhibitions to suppress activity of the two neurons. Significantly, we have shown that the neuropeptide APGWamide that is contained in CBI-3 may mediate the slow inhibition. The ability of single neurons to elicit both fast conventional and slow peptidergic synaptic potentials has been demonstrated in the sympathetic ganglia of the frog (Jan and Jan, 1982). Recently, contributions that fast and slow transmitters in projection neurons make to pattern selection were described in the crab STNS (Blitz and Nusbaum, 1999; Nusbaum et al., 2001), but in the STNS, these transmitters did not converge on the $\mathrm{CPG}$, because they affected other projection neurons through fast inhibition and the pyloric CPG network through peptidergic actions. Aplysia feeding may represent the first example in which both fast and slow inhibitory actions of higher-order neurons are used to meet unique temporal requirements in motor pattern switching.

\section{REFERENCES}

Bartos M, Nusbaum MP (1997) Intercircuit control of motor pattern modulation by presynaptic inhibition. J Neurosci 17:2247-2256.

Baxter DA, Patel VC, Byrne JH (1997) Computational model of a multifunctional central pattern generator $(\mathrm{CPG})$ that underlies consummatory feeding behavior of Aplysia. Soc Neurosci Abstr 23:1044.

Blitz DM, Nusbaum MP (1997) Motor pattern selection via inhibition of parallel pathways. J Neurosci 17:4965-4975.

Blitz DM, Nusbaum MP (1999) Distinct functions for cotransmitters mediating motor pattern selection. J Neurosci 19:6774-6783.

Blitz DM, Christie AE, Coleman MJ, Norris BJ, Marder E, Nusbaum MP (1999) Different proctolin neurons elicit distinct motor patterns from a multifunctional neuronal network. J Neurosci 19:5449-5463.

Calabrese RL, Nadim F, Olsen OH (1995) Heartbeat control in the medicinal leech: a model system for understanding the origin, coordination, and modulation of rhythmic motor patterns. J Neurobiol 27:390-402.

Church PJ, Lloyd PE (1994) Activity of multiple identified motor neurons recorded intracellularly during evoked feedinglike motor programs in Aplysia. J Neurophysiol 72:1794-1809.

Cohen JL, Weiss KR, Kupfermann I (1978) Motor control of buccal muscles in Aplysia. J Neurophysiol 41:157-180.

Coleman MJ, Meyrand P, Nusbaum MP (1995) A switch between two modes of synaptic transmission mediated by presynaptic inhibition. Nature 378:502-505.
Combes D, Meyrand P, Simmers J (1999a) Motor pattern specification by dual descending pathways to a lobster rhythm-generating network. J Neurosci 19:3610-3619.

Combes D, Meyrand P, Simmers J (1999b) Dynamic restructuring of a rhythmic motor program by a single mechanoreceptor neuron in lobster. J Neurosci 19:3620-3628.

Croll RP, Davis WJ, Kovac MP (1985) Neural mechanisms of motor program switching in the mollusc Pleurobranchaea. III. Role of the paracerebral neurons and other identified brain neurons. J Neurosci 5:64-71.

Cropper EC, Kupfermann I, Weiss KR (1990) Differential firing patterns of the peptide-containing cholinergic motor neurons B15 and B16 during feeding behavior in Aplysia. Brain Res 522:176-179.

Delcomyn F (1980) Neural basis of rhythmic behavior in animals. Science 210:492-498.

DiCaprio RA (1990) An interneurone mediating motor programme switching in the ventilatory system of the crab. J Exp Biol 154:517-535.

Dickinson PS, Moulins M (1992) Interactions and combinations between different networks in the stomatogastric nervous system. In: Dynamic biological networks: the stomatogastric nervous system (HarrisWarrick RM, Marder E, Selverston AI, Moulins M, eds), pp 139-160. Cambridge, MA: MIT.

Evans CG, Cropper EC (1998) Proprioceptive input to feeding motor programs in Aplysia. J Neurosci 18:8016-8031.

Gardner D (1971) Bilateral symmetry and interneuronal organization in the buccal ganglia of Aplysia. Science 173:550-553.

Gardner D (1977) Interconnections of identified multiaction interneurons in buccal ganglia of Aplysia. J Neurophysiol 40:349-361.

Harris-Warrick RM, Marder E (1991) Modulation of neural networks for behavior. Annu Rev Neurosci 14:39-57.

Harris-Warrick RM, Nagy F, Nusbaum MP (1992) Neuromodulation of stomatogastric networks by identified neurons and transmitters. In: Dynamic biological networks: the stomatogastric nervous system (Harris-Warrick RM, Marder E, Selverston AI, Moulins M, eds), pp 87-137. Cambridge, MA: MIT.

Hurwitz I, Susswein AJ (1996) B64, a newly identified central pattern generator element producing a phase switch from protraction to retraction in buccal motor programs of Aplysia californica. J Neurophysiol 75:1327-1344.

Hurwitz I, Goldstein RS, Susswein AJ (1994) Compartmentalization of pattern-initiation and motor functions in the B31 and B32 neurons of the buccal ganglia of Aplysia californica. J Neurophysiol 71:1514-1527.

Hurwitz I, Neustadter D, Morton DW, Chiel HJ, Susswein AJ (1996) Activity patterns of the B31/B32 pattern initiators innervating the I2 muscle of the buccal mass during normal feeding movements in Aplysia californica. J Neurophysiol 75:1309-1326.

Hurwitz I, Kupfermann I, Susswein AJ (1997) Different roles of neurons B63 and B34 that are active during the protraction phase of buccal motor programs in Aplysia californica. J Neurophysiol 78:1305-1319.

Hurwitz I, Perrins R, Xin Y, Weiss KR, Kupfermann I (1999) C-PR neuron of Aplysia has differential effects on "feeding" cerebral interneurons, including myomodulin-positive CBI-12. J Neurophysiol 81:521-534.

Hurwitz I, Kupfermann I, Weiss KR (2000) Dual inhibition allows the command-like neuron CBI-2 to generate rhythmic motor programs. Soc Neurosci Abstr 26:450.

Jan LY, Jan YN (1982) Peptidergic transmission in sympathetic ganglia of the frog. J Physiol (Lond) 327:219-246.

Jing J, Weiss KR (2000) Multiplicity of interneurons and diversity of their synaptic connections contribute to multifunctionality of Aplysia feeding motor network. Soc Neurosci Abstr 26:450.

Jing J, Weiss KR (2001) Functional specificity of two novel protractionphase interneurons that contribute to ingestive motor programs in Aplysia. Soc Neurosci Abstr, in press.

Jing J, Morgan PT, Hurwitz I, Cropper EC, Weiss KR (1999) Differential roles of buccal elements of the feeding central pattern generator (CPG) in switching CBI-2-induced motor programs in Aplysia. Soc Neurosci Abstr 25:1643.

Kabotyanski EA, Baxter DA, Byrne JH (1998) Identification and characterization of catecholaminergic neuron B65, which initiates and modifies patterned activity in the buccal ganglia of Aplysia. J Neurophysiol 79:605-621.

Kupfermann I (1974) Feeding behavior in Aplysia: a simple system for the study of motivation. Behav Biol 10:1-26.

Lechner HA, Baxter DA, Byrne JH (2000) Classical conditioning of feeding in Aplysia: I. Behavioral analysis. J Neurosci 20:3369-3376.

Marder E, Calabrese RL (1996) Principles of rhythmic motor pattern generation. Physiol Rev 76:687-717.

Meyrand P, Simmers J, Moulins M (1994) Dynamic construction of a neural network from multiple pattern generators in the lobster stomatogastric nervous system. J Neurosci 14:630-644.

Morgan PT (1999) Contributions of extrinsic and intrinsic neuromodulation to the selection and modification of rhythmic motor behavior. $\mathrm{PhD}$ dissertation, Mount Sinai School of Medicine.

Morgan PT, Jing J, Vilim FS, Weiss KR (2001) Interneuronal and pep- 
tidergic control of motor pattern switching in Aplysia. J Neurophysiol, in press.

Morton DW, Chiel HJ (1993a) In vivo buccal nerve activity that distinguishes ingestion from rejection can be used to predict behavioral transitions in Aplysia. J Comp Physiol 172:17-32.

Morton DW, Chiel HJ (1993b) The timing of activity in motor neurons that produce radula movements distinguishes ingestion from rejection in Aplysia. J Comp Physiol 173:519-536.

Nargeot R, Baxter DA, Byrne JH (1997) Contingent-dependent enhancement of rhythmic motor patterns: an in vitro analog of operant conditioning. J Neurosci 17:8093-8105.

Nargeot R, Baxter DA, Byrne JH (1999) In vitro analog of operant conditioning in Aplysia. I. Contingent reinforcement modifies the functional dynamics of an identified neuron. J Neurosci 19:2247-2260.

Nusbaum MP, Blitz DM, Swensen AM, Wood D, Marder E (2001) The roles of co-transmission in neural network modulation. Trends Neurosci 24:146-154.

Plummer MR, Kirk MD (1990) Premotor neurons B51 and B52 in the buccal ganglia of Aplysia californica: synaptic connections, effects on ongoing motor rhythms, and peptide modulation. J Neurophysiol 63:539-558.

Rosen S, Miller MW, Weiss KR, Kupfermann I (1988) Activity of CBI-2 of Aplysia elicits biting-like responses. Soc Neurosci Abstr 14:608.

Rosen SC, Teyke T, Miller MW, Weiss KR, Kupfermann I (1991) Identification and characterization of cerebral-to-buccal interneurons implicated in the control of motor programs associated with feeding in Aplysia. J Neurosci 11:3630-3655.

Rosen SC, Weiss KR, Kupfermann I (1997) Functional specificity of a command-like interneuron in the feeding system of Aplysia. Soc Neurosci Abstr 23:1045.

Rosen SC, Miller MW, Evans CG, Cropper EC, Kupfermann I (2000) Diverse synaptic connections between peptidergic radula mechanoafferent neurons and neurons in the feeding system of Aplysia. J Neurophysiol 83:1605-1620.

Sanchez JA, Kirk MD (2000) Short-term synaptic enhancement modulates ingestion motor programs of Aplysia. J Neurosci 20:RC85:1-7.

Stein PS, Grillner S, Selverston AI, Stuart DG, eds (1997) Neurons, networks, and motor behavior. Cambridge, MA: MIT.

Susswein AJ, Byrne JH (1988) Identification and characterization of neurons initiating patterned neural activity in the buccal ganglia of Aplysia. J Neurosci 8:2049-2061.

Susswein AJ, Schwarz M, Feldman E (1986) Learned changes of feeding behavior in Aplysia in response to edible and inedible foods. J Neurosci 6:1513-1527.

Teyke T, Rosen SC, Weiss KR, Kupfermann I (1993) Dopaminergic neuron-B20 generates rhythmic neuronal activity in the feeding motor circuitry of Aplysia. Brain Res 630:226-237.

Warman EN, Chiel HJ (1995) A new technique for chronic single-unit extracellular recording in freely behaving animals using pipette electrodes. J Neurosci Methods 57:161-169.

Weiss KR, Koch UT, Koester J, Rosen SC, Kupfermann I (1982) The role of arousal in modulating feeding behavior of Aplysia: neural and behavioral studies. In: The neural basis of feeding and reward (Hoebel BG, Novin D, eds), pp 25-57. Brunswick, ME: Haer Institute.

Wood DE, Stein W, Nusbaum MP (2000) Projection neurons with shared cotransmitters elicit different motor patterns from the same neural circuit. J Neurosci 20:8943-8953. 